\title{
Species of the genus Folsomia (Collembola: Isotomidae) of northern Asia
}

\author{
Mikhall B. POTAPOV ${ }^{1}$ and AnAtoly B. BABENKO ${ }^{2}$ \\ 'Moscow State Pedagogical University, Department of Zoology and Ecology, Kibalchicha str. 6, build. 5, Moscow 129278, Russia \\ ${ }^{2}$ Severtsov Institute of Ecology and Evolution, Russian Academy of Sciences, Leninsky pr. 33, Moscow 117071, Russia
}

Key words. Collembola, Isotomidae, Folsomia, northern Palaearctic, revision, distribution, key

\begin{abstract}
This paper deals with the taxonomy and distribution of Folsomia species from northern Russia with special reference to the Asian regions. Eight new species are described: F. amplissima sp. n., F. ancestor sp. n., F. atropolaris sp. n., F. borealis sp. n., $F$. brevisensilla sp. n., $F$. cryptophila sp. n., F. longidens sp. n., F. palaearctica sp. n. Five species, F. taimyrica, F. regularis, $F$. sp. aff. altamontana, F. alpha, and $F$. janstachi (nom. n. for Isotomina gracilis Stach, 1962 nec Folsomia gracilis Latzel, 1922), are redescribed. $F$. binoculata (Wahlgren) has been recovered and redescribed. The positions of $F$. macrochaetosa, $F$. magadani, and $F$. tesari have been defined more exactly on the basis of type material. An identification key of the northern Asiatic species of the genus is given.
\end{abstract}

\section{INTRODUCTION}

Folsomia is among the largest genera of the Isotomidae. The members of the genus predominate in most collembolan communities of the Palaearctic, especially in the northernmost areas. Nevertheless, the taxonomy of the species inhabiting the Russian Arctic remains unclear, since more attention has been paid by Russian taxonomists to Middle Asia and southern regions of Siberia.

The present paper is concerned with the fauna and distribution of Folsomia species in the tundra and partly taiga zones of Russia with special reference to the Asian regions. It is based on a large quantity of material collected during several expeditions to the Arctic by the authors as well as by other scientists.

\section{LIST OF LOCALITIES AND COLLECTORS}

(Fig. 1)

High Arctic Islands (AR)

Norway, Spitsbergen (SPITS)

Loc. 1. Hornsund, leg. A. Uvarov, viii.1989.

Loc. 2. Edgeoya Island, leg. I. Vtorov, viii.1990.

Franz Josef Land Archipelago (FJL)

Loc. 3. Alexandra Land, leg. V. Bulavintsev, ix.1986.
Loc. 4. Hooker Island, leg. V. Bulavintsev, ix.1986.

Loc. 5. Rudolf Island, leg. V. Bulavintsev, ix.1986.

Loc. 6. Kheis Island, leg. V. Bulavintsev, ix.1986.

Loc. 7. Graham Bell Island, leg. V. Bulavintsev, ix.1986.

Novaya Zemlya Archipelago (NOVZEM)

Loc. 8. Zemlya Pan'kova $\left(73^{\circ} 04^{\prime} \mathrm{N}, 53^{\circ} 10^{\circ} \mathrm{E}\right)$, leg. S. Goryachkin, vii. 1995.

Loc. 9. Mys Zhelaniya, leg. G. Khakhin, viii.1998.

Severnaya Zemlya Archipelago (SEVZEM)

Loc. 10. Komsomolets Island, leg. V. Bulavintsev, vii.-viii. 1991.

Loc. 11. Bol'shevik Island, Vise Point, leg. V. Bulavintsev, vii.1991.

Loc. 12. Bol'shevik Island, Solnechnaya Bay, leg. V. Bulavintsev, vii.1991, leg. O. Makarova, vii.-viii.1997.

Novosibirsk Islands (NOVISL)

Loc. 13. Bel'kovsky Island $\left(75^{\circ} 00^{\circ} \mathrm{N}, 139^{\circ} 50^{\circ} \mathrm{E}\right)$, leg. V. Bulavintsev, vii.1990, leg. A. Babenko, vii. 1994.

Loc. 14. Stolbovoi Island, leg. V. Bulavintsev, vii.1990.

Loc. 15. Zhokhova Island, leg. V. Bulavintsev, vii.1990,

Loc. 16. Kotel'nyi Island, Balyktakh River $\left(75^{\circ} 03^{\circ} \mathrm{N}\right.$, 140¹0`E), leg. A. Babenko, vii. 1994.

Loc. 17. Bol'shoi Lyakhovsky Island, leg. V. Bulavintsev, vii. 1990 .

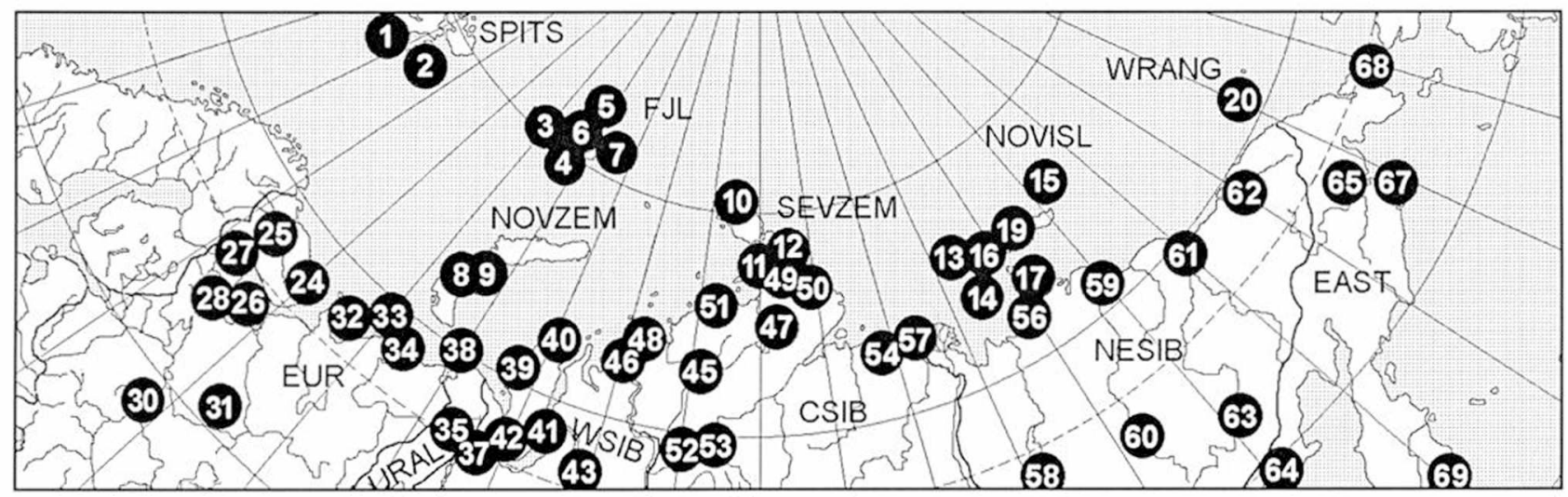

Fig.1. Distribution of sampling localities (see list of localities and collectors). 
Loc. 18. Bunge Land, leg. V. Bulavintsev, vii.1990, A. Babenko, viii. 1994 (same as loc. 16 in Fig. 1).

Loc. 19. Faddeev Island, Ulakhar-Uryakh River $\left(75^{\circ} 35^{\circ} \mathrm{N}\right.$, 1445ㅇE), leg. A. Babenko, vii.1994.

Wrangel Island (WRANG)

Loc. 20. Mamontovaya River $\left(70^{\circ} 58^{\prime} \mathrm{N}, 179^{\circ} 34^{\prime} \mathrm{E}\right)$, leg. A. Babenko, vii. 1994.

Loc. 21. Somnitel'naya Bay, leg. V. Chelnokov, vii.1971.

Canada, NWT (NWT)

Loc. 22. Devon Island, Truelove lowland, leg. A. Babenko, vii. 1991.

Loc. 23. Ellesmere Island, Swerdrup Pass, leg. A. Babenko, vii.1991.

\section{North of European part of Russia (EUR)}

Loc. 24. Kola Peninsula, Kochkovka River $\left(67^{\circ} 25^{\prime} \mathrm{N}\right.$, $40^{\circ} 50^{\prime}$ E), leg. A. Babenko, viii.-ix. 1994.

Loc. 25. Kola Peninsula, Khibin Mts, near Kirovsk, leg. M. Potapov, viii. 1986.

Loc. 26. White Sea, Solovetskie Islands, leg. M. Potapov, vii. 1985.

Loc. 27. Karelia, White Sea, Belomorskaya station, leg. S. Firsova, vii.1976, leg. O. Makarova, viii. 1992.

Loc. 28. Karelia, White Sea, Pon'goma, leg. M. Potapov, viii.1995.

Loc. 29. Karelia, White Sea, Kandalaksha Bay, leg. M. Potapov, viii.1986.

Loc. 30. Vologodskaya Region, Darvinsky Nature Reserve, leg. N. Kuznetsova, vi.1982.

Loc. 31. Southern part of Archangelsk Region, Ramen'e, leg. M. Potapov, viii.1981.

Loc. 32. Kanin Peninsula, Rybnaya River $\left(68^{\circ} 12^{\circ} \mathrm{N}\right.$, $46^{\circ} 10^{\prime} \mathrm{E}$ ), leg. A. Babenko, viii.1994.

Loc. 33. Kolguev Island, Gol'tsovaya River $\left(69^{\circ} 12^{\prime} \mathrm{N}\right.$, $\left.49^{\circ} 30^{\prime} \mathrm{E}\right)$, leg. A. Babenko, viii.1994.

Loc. 34. Pechora Bay, Kuznetskoe lake $\left(68^{\circ} 50^{\prime} \mathrm{N}, 53^{\circ} 45^{\prime} \mathrm{E}\right)$, leg. A. Babenko, viii.1994.

Loc. 35. Komi Republic, near Sivomaskinsky, Kuz-di-Shor, N. Kuznetsova, vii.1978.

\section{Ural (URAL)}

Loc. 36. North Ural, Pechoro-Ilychsky Nature Reserve, leg. L. Pospelov, viii. 1972.

Loc. 37. North Ural, Salekhard, leg. I. Stebaev, vii.1957.

Loc. 38. Vaigach Island, leg. V. Bulavintsev, vii.1987.

\section{North-western Siberia (WSIB)}

Loc. 39. Yamal, Myrtyyakha River $\left(70^{\circ} 18^{\prime} \mathrm{N}, 67^{\circ} 53^{\prime} \mathrm{E}\right)$, leg. A. Babenko, viii. 1994.

Loc. 40. Yamal, mouth of Yakhadeyakha River $\left(72^{\circ} 52^{\prime} \mathrm{N}\right.$, $70^{\circ} 56^{\prime} \mathrm{E}$ ), leg. A. Babenko, viii. 1994.

Loc. 41. Yamal, Kamenny Nos Point, leg. V. Nikolsky, 1979.

Loc. 42. Southern Yamal, Schuch'e, leg. A. Tikhomirova, vii.1971, leg. P. Basikhin, vii. 1984.

Loc. 43. Tazovsky Peninsula, Pur-Taz, leg. I. Vtorov, viii. 1989.

Loc. 44. Middle current of Yenisei River $\left(62^{\circ} 20^{\prime} \mathrm{N}\right)$, leg. K. Eskov, viii. 1978 .

\section{Northern part of the central Siberia (CSIB)}

Loc. 45. Taimyr, Tareya settlement, spotted tundra, leg. Yu. Chernov, vii. 1966.

Loc. 46. Taimyr, mouth of Ragozinka River, leg. A. Babenko, vii.-viii.1986.

Loc. 47. Taimyr, northern shore of Taimyr lake, leg. A. Babenko, vii.-viii. 1993.
Loc. 48. Tainyr, mouth of Uboinaya River, leg. A. Babenko, vii.-viii.1988

Loc. 49. Taimyr, Chelyuskin Point, Serebryanka River $\left(77^{\circ} 36^{\prime} \mathrm{N}, 103^{\circ} 49^{\prime} \mathrm{E}\right)$, leg. A. Babenko, viii.1994.

Loc. 50. Taimyr, Faddeya shore, Rybnaya River $\left(76^{\circ} 38^{\prime} \mathrm{N}\right.$, $111^{\circ} 00^{\prime}$ E), leg. A. Babenko, viii. 1994.

Loc. 51. Taimyr, Laptev shore, Middendorf Bay, Opalovaya

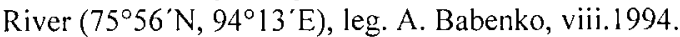

Loc. 52. Plateau Putorana, Dynkengda Mt., Yt-kyuel lake $\left(69^{\circ} 08^{\prime} \mathrm{N}, 91^{\circ} 50^{\prime} \mathrm{E}\right)$, leg. A. Babenko, viii.1996, vii. 1997.

Loc. 53. Plateau Putorana, Ayan River, leg. V. Karpov, ix.1989.

Loc. 54. Delta of Olenek River, Vaganytta-Kyuel lake $\left(73^{\circ} 30^{\prime} \mathrm{N}, 118^{\circ} 10^{\prime} \mathrm{E}\right)$, leg. A. Babenko, vii. 1994.

Loc. 55. Central Yakutia, $17 \mathrm{~km}$ from Yakutsk to Tabaga, leg. M. Potapov, vii. 1992.

\section{North-eastern Siberia (NESIB)}

Loc. 56. Delta of Yana River, Shirokostan Peninsula, Ledyanoe lake $\left(72^{\circ} 25^{\prime} \mathrm{N}, 141^{\circ} 00^{\prime} \mathrm{E}\right)$, leg. A. Babenko, viii. 1994.

Loc. 57. Mouth of Lena River, Kuba Island, leg. V. Bulavintsev, viii.1985

Loc. 58. Yakutia, Verkhoyansky Range, Kele River $\left(64^{\circ} 30^{\prime} \mathrm{N}, 132^{\circ} \mathrm{E}\right)$, leg. G. Lukovtsev, vii.1989.

Loc. 59. Delta of Indigirka River $\left(71^{\circ} 26^{\prime} \mathrm{N}, 149^{\circ} 45^{\prime} \mathrm{E}\right)$, leg. A. Babenko, vii.1994.

Loc. 60. North-eastern Yakutia, middle current of Indigirka River, Ust-Nera, leg. M. Potapov, vii.1992.

Loc. 61. Delta of Kolyma River, left low bank $\left(69^{\circ} 32^{\prime} \mathrm{N}\right.$, $160^{\circ} 44^{\prime}$ E), leg. A. Babenko, vii. 1994.

Loc. 62. Northern Chukotka, Chaun Bay, leg. S. MacLean, 1976.

Loc. 63. Upper current of Kolyma River, Aborigen station, leg. D. Berman, viii.-x.1987, ix.1995.

\section{Far East (EAST)}

Loc. 64. Vicinity of Magadan, Snezhnaya Valley, leg. D. Berman, ix.1974.

Loc. 65. Central Chukotka, El'gygytgyn Lake, leg. E. Bondarenko, viii.1974.

Loc. 66. Central Chukotka, Volchikha River, leg. E. Bondarenko, viii.1972.

Loc. 67. Chukotka, Beringovsky district, Ugol'naya Bay, leg. M. Chernyakhovsky, vii.-viii.1987.

Loc. 68. Eastern Chukotka, Bering Strait, Chegitun River, leg. I. Netushilin.

Loc. 69. Kamchatka, Kronotsky Nature Reserve, leg. O. Kapustyants, viii.1987.

\section{Other northern localities (OTHNOR)}

Loc. 70. Finland, Utsjoki, Kevo Nature Reserve, leg. S. Kopponen, viii. 1986

Loc. 71. Alaska, Pt. Barrow, leg. S. MacLean, 1975.

\section{Southern localities (SOUTH)}

Loc. 72. Southern Siberia, Baikal, Bol'shoye Goloustnoe, leg. M. Kalinin, viii. 1990.

Loc. 73. Southern Siberia, Tuva, Sangilen, leg. S. Stebaeva, viii. 1995.

Loc. 74. South-western Siberia, Khakassia, West Sajan Range, Bol'shoi On, leg. S. Iordansky, viii. 1989.

Loc. 75. South-western Siberia, Khakassia, West Sajan

Range, Novorossiyskoe, leg. S. Stebaeva, vi.1990.

Loc. 76. Western Ukraine, Carpathian Mts, leg. N. Kuznetsova, x.1982.

Loc. 77. Poland, Tatry, leg. M. Potapov, i.1995. 

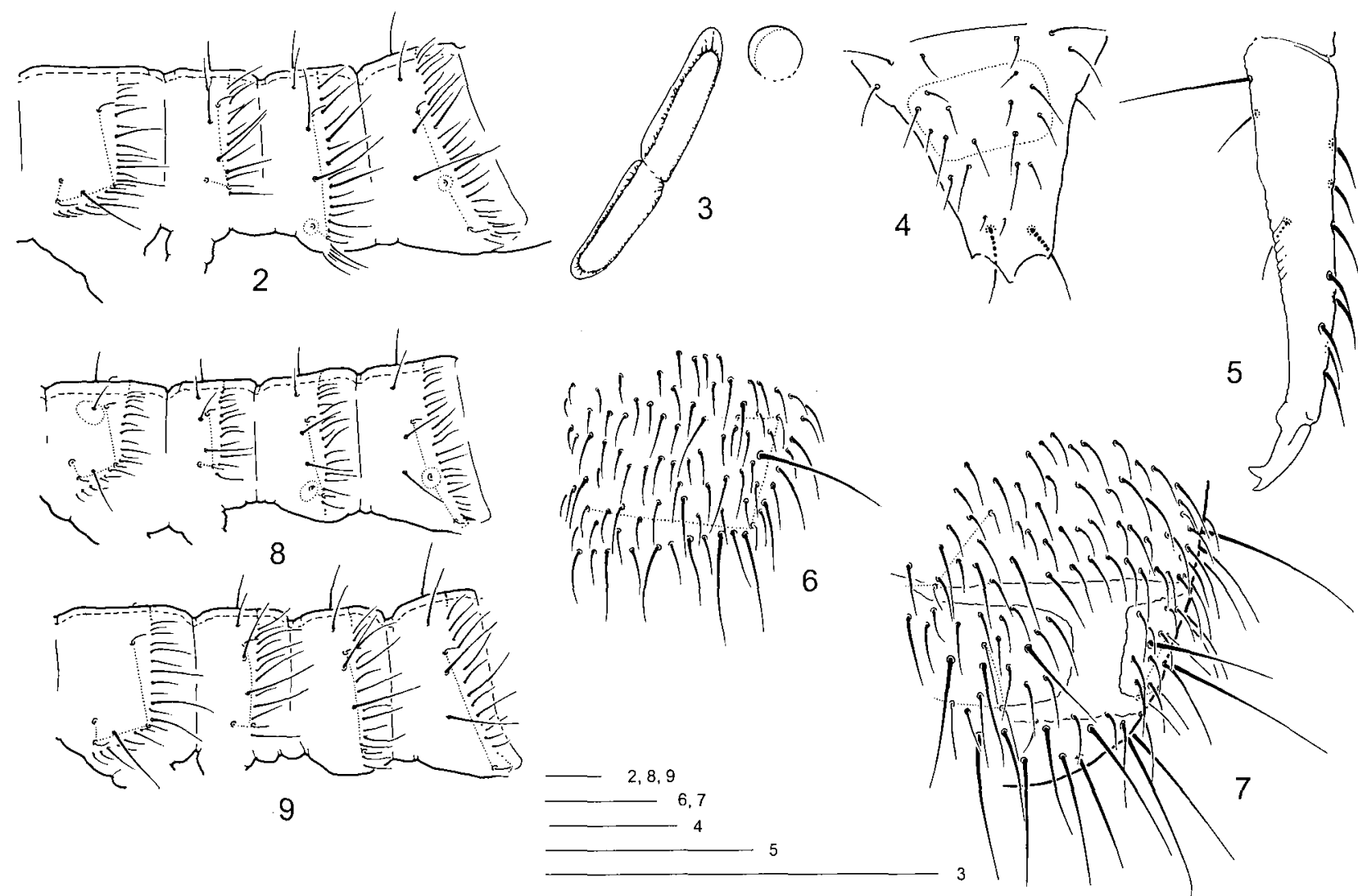

Figs 2-9. 2-7: F. borealis sp. n. 2 - arrangement of sensilla, microsensilla and macrochaetae on Th. III-Abd. III; 3 - PAO and ommatidium; 4 - chaetotaxy of manubrium; 5 -dens laterally; 6 - lateral part of Th. III; 7 - dorsal chaetotaxy of the end of abdomen (the part of the surface with more rugose granulation is traced). $8-F$. taimyrica, arrangement of sensilla, microsensilla and macrochaetae on Th. III-Abd. III; $9-F$. amplissima, dtto. Scale: $0.1 \mathrm{~mm}$.

Abbreviation of collections: ZMAS - Zoological Institute, St. Petersburg, MSPU - Moscow State Pedagogical University, AB - A. Babenko.

\section{TAXONOMY AND DISTRIBUTION}

31 Folsomia species have been found in the Asian region of the northern Palaearctic, including 8 new to science. They can be split into several groups based on the sensilla position on the terga and some traditional characters.

Group A: with medial accp-sensilla far in front of $\mathrm{p}$ row of dorsal chaetae.

With $1+1$ anterior chaetae on manubrium:

$F$. taimyrica complex: $F$. taimyrica, $F$. borealis, $F$. amplissima.

F. quadrioculata complex: F. quadrioculata, F. manolachei, $F$. palaearctica, $F$. sp. n. aff. palaearctica.

With $2+2$ or more anterior chaetae on manubrium:

$F$. regularis complex (with a normal arrangement of sensilla): $F$. regularis, $F$. binoculata, $F$. atropolaris, $F$. sp. aff. ozeana.

$F$. sexoculata complex (with a particular arrangement of sensilla): $F$. sexoculata, $F$. diplophthalma, $F$. cf. diplophthalma, $F$. microchaeta, $F$. sp. aff. altamontana.

Group B: with medial sensilla within or (on thorax) slightly in front of p-row:
$F$ fimetaria complex (with $1+1$ macrochaetae on Th. II and III): $F$. fimetaria, $F$. bisetosa, $F$. ciliata, $F$. cryptophila, $F$. nivalis, $F$. sparsosetosa, $F$. sp. aff. stella.

$F$. macrochaetosa complex (with $2+2$ macrochaetae on Th. II and III): F. macrochaetosa, $F$. brevisensilla.

Group C: with $2+2$ broad sensilla on Abd. V:

$F$. sensibilis complex: $F$. sensibilis, $F$. alpha, $F$. ancestor, $F$. janstachi, $F$. longidens, $F$. magadani.

\section{The $F$. taimyrica complex}

This is characterized by at most $2+2$ ommatidia, $1+1$ chaetae on the anterior side of the manubrium, and the same arrangement of sensilla as the $F$. quadrioculata complex, but differs from the latter by having more chaetae on the lateral flaps of the ventral tube $(4+4$ vs. $3+3)$ and in the central part of the posterior side of manubrium $(4+4-6+6$ vs. $2+2)$. The presence of 2 lateral sensilla on Ant. III is also characteristic of all the northern members of the complex.

Below we divide $F$. taimyrica auct. into three species based on the number of ommatidia and the presence/absence of microsensilla on Abd. II-III and medial macrochaetae on Th. III (Figs 2, 8-9). The relative length of the abdominal macrochaetae can also be used in their separation, particularly during preliminary sorting, but the variation of associated length ratios (macrochaeta : mucro and macrochaeta : dens) are overlapping (Fig. 24). The pro- 

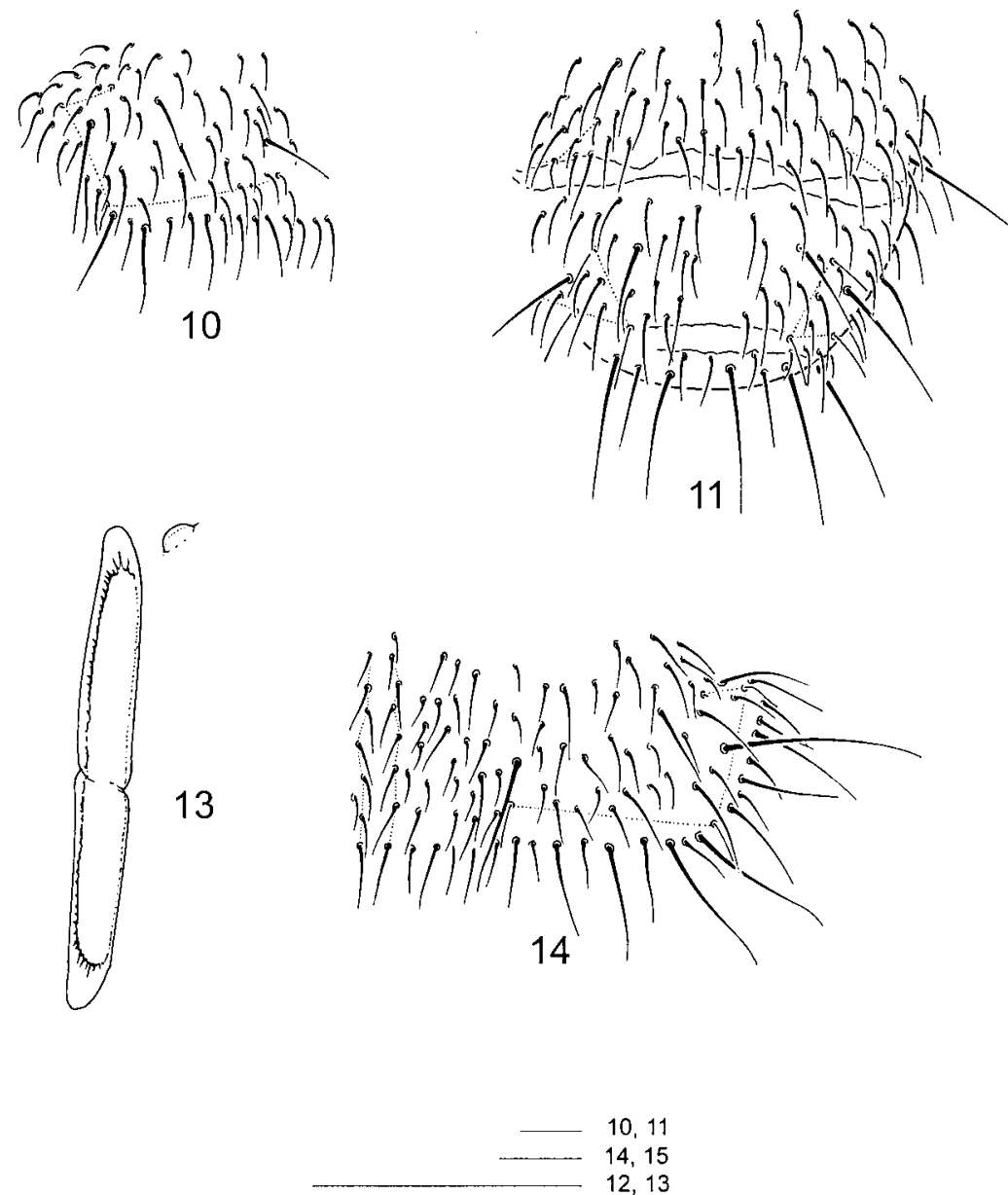

0,11
4,15

2,13

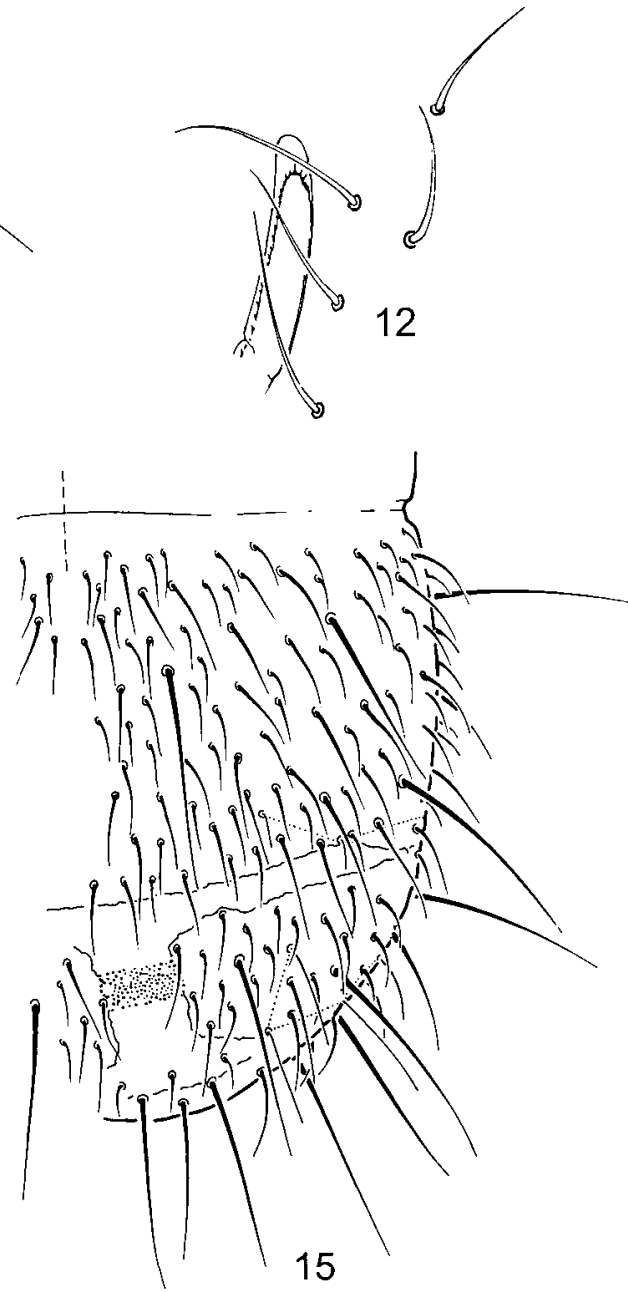

Figs 10-15: F. taimyrica. 10 - chaetotaxy of Th. 111; 11 - chaetotaxy of the end of abdomen; 12 - upper part of PAO; 13 - PAO and remnant of ommatidium; 14 - chaetotaxy of Th. III; 15 - chaetotaxy of Abd. IV-VI. 10-12 - form 2, Severnaya Zemlya; 13 form 1, Wrangel Island; 14,15 - paratypes, Taimyr. Scale: $0.05 \mathrm{~mm}$.

posed division is generally supported by the geographical distribution of the species (Fig. 105).

\section{Folsomia taimyrica Martynova, 1973}

Redescription. White, sometimes with few small grains of dark pigment. Ommatidia usually absent (see also Affinities). PAO narrow, constricted, with inner "denticles" (Fig. 12), distinctly longer than width of Ant. I. Maxillary palp bifurcate, outer maxillary lobe with 4 sublobal hairs.

Labral formula $4 / 5,5,4$. Ventral side of head with $4+4-5+5$ chaetae along linea ventralis. Labium with $4+4$ chaetae. Ant. I, II, III with 3, 3, 1 basal microsensilla and $2,1,6$ sensilla respectively.

Sensillar formula for Th. II-Abd. V: 4,3/2,2,2,3,5 (s), $1,1 / 1,1,1,0,0$ (ms) (Fig. 8). On Th. II-Abd. III medial accp-sensilla are in the middle parts of the segments. Medial sensilla on Abd. IV are slightly in front of, or inside of, the p-row of chaetae. Th. II and III with $1+1$ and $2+2$ macrochaetae, respectively (Fig. 10, 14). Abd. I-III with $3+3$ macrochaetae. The length of the macrochaetae varies from moderate to long (Fig. 24). Thorax without ventral chaetae.
Claw without teeth. Retinaculum with $4+4$ teeth and a chaeta on corpus. Ventral tube with $4+4$ latero-distal chaetae and 6-12 posterior ones. Manubrium anteriorly with a distal pair of chaetae (sometimes with $2+1$ ), posteriorly with $3+3$ latero-basal, $4+4$ central, $2+2$ distal, and 2 apical chaetae. Lateral sides of manubrium with $0+0,0+1$ or $1+1$ chaetae. Dens crenulated, anteriorly with 8 (rarely 9 ), posteriorly with 3 chaetae ( 2 in the basal part and 1 in the middle). Mucro with two teeth.

Material. AR: SPITS Loc. 2, 1 ex., coll. MSPU; FJL Loc. 6 and 7, 64 ex., coll. MSPU; SEVZEM Loc. 10, 124 ex., coll. AB; Loc. 11, 32 ex., coll. AB; Loc. 12, 12 ex., coll. AB; NOVISL Loc. 13-15, 41 ex., coll. MSPU; Loc. 16, 16 ex., coll. AB; Loc. 19, 6 ex., coll. AB; WRANG Loc. 20, 7 ex., coll. AB; WSIB: Loc. 39, 2 ex., coll. AB; CSIB: Loc. 45, 4 ex. (paratypes), coll. ZMAS; Loc. 47, 6 ex., coll. AB; Loc. 49, 3 ex., coll. AB; Loc. 50,8 ex., coll. AB; Loc. 54, 1 ex., coll. AB.

Affinities. After the original description, F. taimyrica may have a small, unpigmented ommatidium (figured in the holotype) but this is often absent. In the four studied paratypes we could not find any cornea, but instead irregular primary granulation in the associated place. However, among many blind individuals from the Wrangel 
Island some specimens with a hardly visible small ommatidium (Fig. 13), similar to that figured by Martynova, have been seen.

Fjellberg (1984) indicated an unusual variability of $F$. taimyrica in the number and size of ommatidia $(0+0,1+1$ or $2+2$ ) and supposed that several species could be involved. We accept here that only specimens characterized by the presence of $2+2$ macrochaetae on Th. III and microsensilla on all terga of Th. II-Abd. III belong to the true $F$. taimyrica. Ommatidia are usually absent.

Even in the proposed restricted diagnosis, the species remains morphologically variable. Our material includes two main forms. As specimens with intermediate characters do also exist, both of them are treated as F. taimyrica here:

Form 1. The largest macrochaetae on abdominal end are 4-5 times longer than mucro. Unsetaceous band on Abd.V granulated (Fig. 15). Rarely it has a small unpigmented ommatidium. Includes the studied paratypes.

Form 2. The largest macrochaetae on abdomen shorter, 2.7-3.7 times longer than mucro. No irregular granulation on unsetaceous band on Abd. V (Fig. 11). No ommatidia.

Distribution. Possibly a circumpolar species (Fig. 105), but Nearctic records should be verified.

$F$. taimyrica $\mathrm{f}$. 1 has a more southern distribution, restricted to the tundra zone, no records from the true polar desert. Recorded from Yamal Peninsula to the Wrangel Island in Russia, but seems to be absent in the eastern part of the mainland.

F. taimyrica f. 2 is one of the commonest forms on the High Arctic archipelagos (from Spitsbergen to Novosibirsk Islands). Also recorded from the northern belt of the tundra zone, for instance on the Taimyr Peninsula.

\section{Folsomia borealis sp. $\mathrm{n}$.}

Description. Body length up to $1.4 \mathrm{~mm}$, usually smaller. White with $1+1$ unpigmented ommatidia. PAO narrow, clearly constricted at the middle, with inner "denticles" (Fig. 3), distinctly longer than the width of Ant. I. Maxillary palp bifurcate, outer maxillary lobe with 4 sublobal hairs.

Labral formula 4/5,5,4. Ventral side of head with $4+4-5+5$ chaetae along linea ventralis. Labium with $4+4$ chaetae. Ant. I, II, III with 3, 3, 1 basal microsensilla and 2, 1, 6 sensilla, respectively.

Body sensilla rather long, about $2 / 3$ as long as common chaetae. Sensillar formula for Th. II-Abd. V: 4,3/2,2,2,3,5 (s), 1,1/1,1,1,0,0 (ms) (Fig. 2). Medial accpsensilla on Th. II-Abd. III are in the middle parts of the segments, those on Abd. IV are slightly in front of p-row of chaetae. On Abd. V three medial sensilla are 2-3 times as long as those on Abd. IV, lateral sensillum shorter, not broad. Both Th. II and Th. III with $1+1$ lateral macrochaetae (Fig. 6). Abd. I-III with $3+3$ smooth macrochaetae on each tergum. The largest macrochaetae of the last abdominal segments 3.5-4.5 times longer than mucro (Fig. 7). Axial chaetom of Th. II-Abd. III: 9-10,8-9 /4-5,4-5,4-5. Thorax without ventral chaetae.

Claw toothless. Fore tibiotarsus with many additional chaetae. Retinaculum with $4+4$ teeth and a chaeta on cor- pus. Ventral tube with $4+4$ latero-distal chaetae and 6-9 posterior ones. Manubrium anteriorly with $1+1$ chaetae; posteriorly with $3+3$ latero-basal, $4+4-5+5(5+6)$ central, $2+2$ distal, and 2 apical chaetae (Fig. 4). Lateral sides of manubrium usually with $1+1$ chaetae. Dens crenulated, with 7-8 anterior chaetae and 3 posterior chaetae ( 2 basal and 1 in the middle part) (Fig. 5). Mucro with two teeth.

The measurements of the holotype are given in Table 2.

Type material. Holotype: $\uparrow$ (slide), labelled "Russia, Central Taimyr, northern shore of Taimyr lake, flood-plain meadow with Lloydia sp., 02.viii.1993", leg. A. Babenko, coll. MSPU. Paratypes: 2 specimens from the same sample; 2 specimens from the same region but "spotted tundra, 13.vii.1993"; and 3 specimens from "peat hummock with dwarf birch, 20.vii.1993", leg. A. Babenko, coll. MSPU.

Additional material. EUR: Loc. 31, 11 ex., coll. MSPU; Loc. 35, 2 ex., coll. MSPU; URAL: Loc. 37, 2 ex., coll. MSPU; Loc. 38, 2 ex., coll. MSPU; WSIB: Loc. 39, 2 ex., coll. AB; Loc. 40, 3 ex., coll. AB; Loc. 41, 1 ex., coll. MSPU; Loc. 42, 1 ex., coll. MSPU; Loc. 43, 1 ex., coll. MSPU; Loc. 44, 5 ex., coll. MSPU; CSIB: Loc. 48, 13 ex., coll. AB; Loc. 54, 2 ex., coll. AB; Loc. 56, 3 ex., coll. AB; NESIB: Loc. 58,7 ex., coll. MSPU; Loc. 60, 82 ex., coll. MSPU; Loc. 63, 3 ex., coll. MSPU.

Name derivation. Named by reason of distribution area of the new species, the main part of which is within the boreal belt.

Affinities. The new species resembles $F$. taimyrica in having microsensilla on all terga from Th. II to Abd. III, but differs in having only $1+1$ macrochaetae on Th. III (the medial ones are not differentiated) and the presence of a large ommatidium.

Distribution. The species has the most southern distribution area among the members of $F$. taimyrica complex (Fig. 105). Widely distributed, inhabiting various communities of the northern taiga and tundra of both Asian and European parts of Russia, but no records from the Kola Peninsula or Karelia.

\section{Folsomia amplissima sp. n.}

Description. Body length up to $1.8 \mathrm{~mm}$. White, with some grains of black pigment scattered mostly on head and last abdominal segments. $2+2$ small ommatidia, the posterior cornea smaller and hardly observable (Fig. 19-22) (see also Affinities). Region of ommatidia usually pigmented. PAO narrow, clearly constricted in the middle, with inner "denticles", distinctly longer than width of Ant. I. Maxillary palp bifurcate, outer maxillary lobe with 4 sublobal hairs.

Labral formula $4 / 5,5,4$. Ventral side of head with $4+4-5+5$ chaetae along linea ventralis. Labium with $4+4$ chaetae. Ant. I, II, III with 3, 3, 1 basal microsensilla and 2, 1, 6 sensilla, respectively.

Body sensilla rather long, $2 / 3$ as long as common chaetae. Sensillar formula for Th. II-Abd. V: 4,3/2,2,2,3,5 (s), 1,1/1,0,0,0,0 (ms) (Fig. 9). Specimens without ms on Th. III on one side are also found. Medial accp-sensilla on Th. II-Abd. III are in the middle parts of the segments, those on Abd. IV slightly in front of p-row of chaetae. On Abd. $V$ the three medial sensilla are $2-3$ times as long as those on Abd. IV, lateral sensillum shorter, not broad. Both Th. II and Th. III with $1+1$ macrochaetae. Abd. 

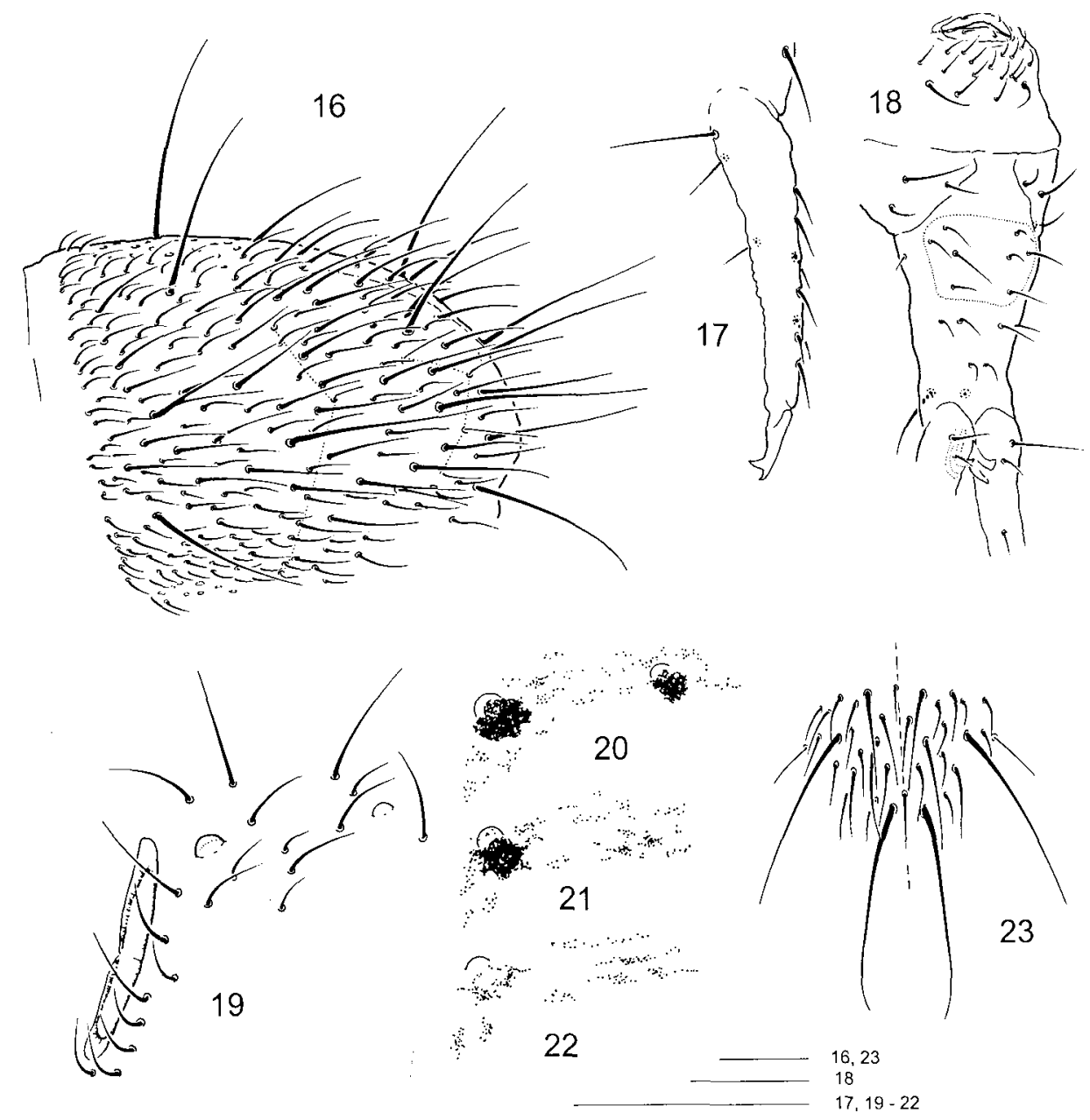

Figs 16-23: F. amplissima sp. n. 16 - dorsal chaetotaxy of Abd. IV-VI; 17 - dens; 18 - furca and genital plate (posterior side); 19 - PAO and ommatidia; 20-21 - pigment arrangement and cornea of ommatidia (Olenek Bay); 22 - dito (Yamal); 23 - dorsal chaetotaxy of medial part of Abd.V-VI. 16-20, 23 - paratypes. Scale: $0.1 \mathrm{~mm}$.

II-III with $3+3$ smooth macrochaetae on each tergum. The largest macrochaetae of abdominal tip 4.6-6.2 times longer than mucro (Fig. 16). Axial chaetom of Th. II-Abd. III: $10-12,9 / 4-6,4-6,4-5$. Thorax without ventral chaetae.

Claw toothless. Fore tibiotarsus with many additional chaetae. Retinaculum with $4+4$ teeth and one chaeta on corpus. Ventral tube with $4+4$ latero-distal chaetae and 7-10 posterior ones. Anterior furcal subcoxa with about 11 chaetae, posterior one with 6 chaetae. Manubrium anteriorly with $1+1$ chaetae; posteriorly with $3+3$ laterobasal, $4+4$ (rarely 3 or 5 on one of the side) central, $2+2$ distal, and 2 apical chaetae (Fig. 18). Lateral sides of manubrium usually with one chaeta. Dens crenulated, anteriorly with 7-8, posteriorly with 3 chaetae ( 2 basal and 1 in the middle part) (Fig. 17). Mucro with two teeth.

Type material. Holotype: ơ (slide), labelled "Russia, Siberia, delta of Olenek River, Vaganytta-Kyuel lake $\left(73^{\circ} 30^{\circ} \mathrm{N}\right.$, $118^{\circ} 10^{\prime} \mathrm{E}$ ), spotted tundra, sedge rim, 06.-08.vii.1994", leg. A. Babenko, coll. MSPU. Paratypes: 3 specimens from the holotype sample; 1 specimen from the same region but "spotted tundra, patch rim"; 5 specimens from "Russia, Siberia, delta of Yana River, Shirokostan Peninsula, Ledyanoe lake $\left(72^{\circ} 25^{\prime} \mathrm{N}\right.$, $\left.141^{\circ} 00^{\prime} \mathrm{E}\right)$, wet sedge slope with Salix polaris, 04.-06.viii.1994"; 2 specimens from "Russia, Siberia, Novosibirsk Islands, Bel'kovski Island, $\left(75^{\circ} 00^{\prime} \mathrm{N}, 139^{\circ} 50^{\circ} \mathrm{E}\right)$, 09.vii. 1994", leg. A. Babenko, coll. MSPU.

Additional material. EUR: Loc. 34, 1 ex., coll. AB; URAL: Loc. 36, 9 ex., coll. MSPU; Loc. 38,7 ex., coll. MSPU; WSIB: Loc. 39, I ex., coll. AB; AR: NOVISL Loc. 15, 6 ex., coll. MSPU; Loc. 16, 7 ex., coll. AB; Loc. 17, 32 ex., coll. MSPU, Loc. 19, 3 ex., coll. AB; NESIB: Loc. 56, 1 I ex., coll. AB; Loc. 59, 3 ex., coll. AB; Loc. 61, 1 ex., coll. AB; Loc. 63, 7 ex., coll. MSPU; EAST: Loc. 65,1 ex., coll. MSPU; Loc. 66,5 ex., coll. MSPU; Loc. 67, 10 ex., coll. MSPU; Loc. 68, 30 ex., coll. MSPU; Loc. 69, 14 ex., coll. MSPU.

Name derivation. It is the largest Folsomia species in the Russian Arctic, which is reflected in its specific name (amplissima - huge in Latin).

Affinities. The new species can be easily distinguished from $F$. taimyrica and $F$. borealis by the absence of microsensilla on Abd. II-III. Besides, F. amplissima has $2+2$ ommatidia, no medial unsetaceous band on Abd. V (Fig. 23), and longer macrochaetae. Due to the $2+2 \mathrm{om}-$ matidia and a single pair of anterior chaetae on manubrium $F$. amplissima can be confused with $F$. quadrioculata, which, however, belongs to another species group characterized by fewer chaetae on the lateral flaps of the ventral tube $(3+3$ chaetae vs. $4+4)$ and on the 
central part of posterior side of manubrium $(2+2$ vs, 4+4-6+6). Habitually the former differs from pale specimens of $F$. quadrioculata by having less diffuse colour pattern and larger pigment grains.

In the material from the westernmost part of the distribution area of $F$. amplissima we found some populations without pigment in the ocular area and without distinct cornea, but with only irregular primary granulation in their places (open circles on Fig. 105). Their status calls for further study.

Distribution. Widespread in the Arctic and Subarctic from the western slope of Ural Mts range to Chukotka, but seems to be more numerous in the eastern part of the area (Fig. 105).

\section{The $F$. quadrioculata complex}

The members of this complex are very similar to the previous group but have fewer chaetae on the lateral flaps of ventral tube $(3+3$ chaetae vs. $4+4$ in $F$. taimyrica complex) and in the central part of the posterior side of manubrium $(2+2$ vs. $4+4-6+6)$. Four species of this complex are permanent inhabitants of the northern regions of the Palaearctic, namely $F$. quadrioculata, $F$. manolachei, $F$. palaearctica sp. n., and $F$. sp. n. aff. palaearctica. The two latter species were previously recorded from the northern Palaearctic as $F$. diplophthalma which is now redefined as a member of the $F$. sexoculata complex (Potapov \& Dunger, in press).

\section{Folsomia quadrioculata (Tullberg, 1871)}

Affinities. We separate $F$. quadrioculata from $F$. manolachei using the characters proposed by Deharveng (1982). Unfortunately after his paper the problem of a broad diagnosis of $F$. quadrioculata has been replaced by the problem of a broad diagnosis of $F$. manolachei, which is usually listed as "manolachei complex" in recent publications.

It is often considered that $F$. quadrioculata has a preference for colder and wetter habitats than $F$. manolachei. According to our data, $F$. quadrioculata is indeed much more frequent and abundant in the northern areas of the Palaearctic, but as a whole, the distribution areas of both species in the Arctic are strongly overlapping.

Distribution. Holarctic. Almost all over the northern part of Russia, excluding some of the High Arctic archipelagos. More common in the southern tundra subzones. Spitsbergen, Novaya Zemlya, central parts of Taimyr and Wrangel Island are the northernmost areas of its distribution.

\section{Folsomia manolachei Bagnall, 1939 sensu Deharveng, 1982}

Affinities. The species often predominates in many southern areas of Russia and is also rather common in the Arctic. This fact supports the opinion that $F$. manolachei is a complex of several morphologically hardly distinguishable species.

Distribution. Scattered records all over the northern Palaearctic, much more frequent in the western part. Not found in the High Arctic and, unlike F. quadrioculata, it is not recorded from Spitsbergen (Fjellberg, 1994), Novaya Zemlya and Wrangel Island.

\section{Folsomia palaearctica sp. n.}

Folsomia diplophthalma auct. nec Axelson, 1902.

Description. Body length up to $0.7 \mathrm{~mm}$. Colour varies, usually spotty grey due to large and scattered pigment grains, the end of abdomen clearly paler, unlike most Folsomia. Sometimes pale or without pigment on body, eye spots always coloured. $1+1$ ommatidia. PAO elongated, 5-6 times as long as ommatidia, with indistinct constriction, clear "denticles" missing (Fig. 32). Maxillary palp bifurcated, outer maxillary lobe with 4 sublobal hairs.

Labral formula $4 / 5,5,4$. Ventral side of head with $4+4$ chaetae along linea ventralis. Labium with $4+4$ chaetae. Ant. I, II, III with $3(=2+1), 3,0$ basal microsensilla, and with $2,1,5$ ( 2 inner, 2 outer and 1 latero-apical) sensilla respectively. Apical organite on Ant. IV roundish (Fig. 33).

Body sensilla slightly shorter than common chaetae, well differentiated. Sensillar formula for Th. II-Abd. V: $4,3 / 2,2,2,3,5$ (s), 1,0/1,0,0,0,0 (ms). Hind corner of Th. II with lateral sensillum well in front of the p-row (Fig. 31 ). Medial accp-sensilla on Th. II-Abd. III are situated far in front of the p-row, those on Abd. IV clearly in front of the p-row. On Abd. V the three medial sensilla are 2.0-2.5 times as long as those on Abd. IV. Lateral sensillum thickened. Macrochaetae short (Fig. 35), the longest on abdominal tip are 2.7-3.5 times as long as mucro. Macrochaetal formula typical for the genus $(1,1 / 3,3,3,4)$. As a whole there are rather few chaetae on the body: Th. III with 20-23 p-chaetae, Abd. I-III with only 3-4 axial chaetae on each side. Thorax without ventral chaetae.

Claw toothless. Fore tibiotarsus usually with 21 chaetae. Upper and lower subcoxa with 1 and 6-8 (leg II), 2-4 and 6-7 (leg III) chaetae respectively. Retinaculum with $4+4$ teeth and one chaeta on corpus. Ventral tube with $3+3$ latero-distal chaetae and $6-7$ posterior ones (Fig. 30). Anterior furcal subcoxa as a rule with 3 (rarely 2 or 4 ) chaetae, the posterior one usually with 3 chaetae. Furca short. Anterior side of manubrium with $1+1$ apical chaetae, posterior one with $3+3$ latero-basal, $2+2$ central, $2+2$ distal, and $1+1$ apical chaetae (Fig. 36). Lateral sides of manubrium with one chaeta. Dens partly crenulated, usually with $7(1,1,2,3)$ anterior and 3 posterior chaetae $(2$ basal and 1 in the middle part) (Fig. 34). Mucro with 2 teeth. Manubrium : dens : mucro as $3-5: 3-4: 1$.

Type material. Holotype: $q$ (slide), labelled "Russia, Novaya Zemlya Archipelago, northern part of Southern Island, Zemlya Pan'kova $\left(73^{\circ} 04^{\prime} \mathrm{N}, 53^{\circ} 10^{\prime} \mathrm{E}\right)$, willow, mosses, Dryas, 1995", leg. S. Goryachkin, coll. MSPU. Paratypes: 33 specimens from the same sample.

Additional material. OTHNOR: Loc. 70, 3 ex., coll. MSPU; EUR: Loc. 25, 5 ex., coll. MSPU; Loc. 32, 4 ex., coll. AB; Loc. 33, 9 ex., coll. AB; CSIB: Loc. 46, 32 ex., coll. AB; Loc. 47, 5 ex., coll. $A B$; Loc. 48, 2 ex., coll. AB; Loc. 52, 18 ex., coll. $A B$; Loc. 53, 123 ex., coll. MSPU; Loc. 54, 2 ex., coll. AB; AR: NOVISL Loc. 13, 3 ex., coll. AB; Loc. 16, 5 ex., coll. AB; Loc. 19, 4 ex., coll. AB; NWT Loc. 22, 24 ex., coll. AB; CSIB: Loc. 55 , 6 ex., coll. MSPU; NESIB: Loc. 56,7 ex., coll. AB; Loc. 58, 2 ex., coll. MSPU; Loc. 60, 62 ex., coll. MSPU; Loc. 61, 10 ex., 


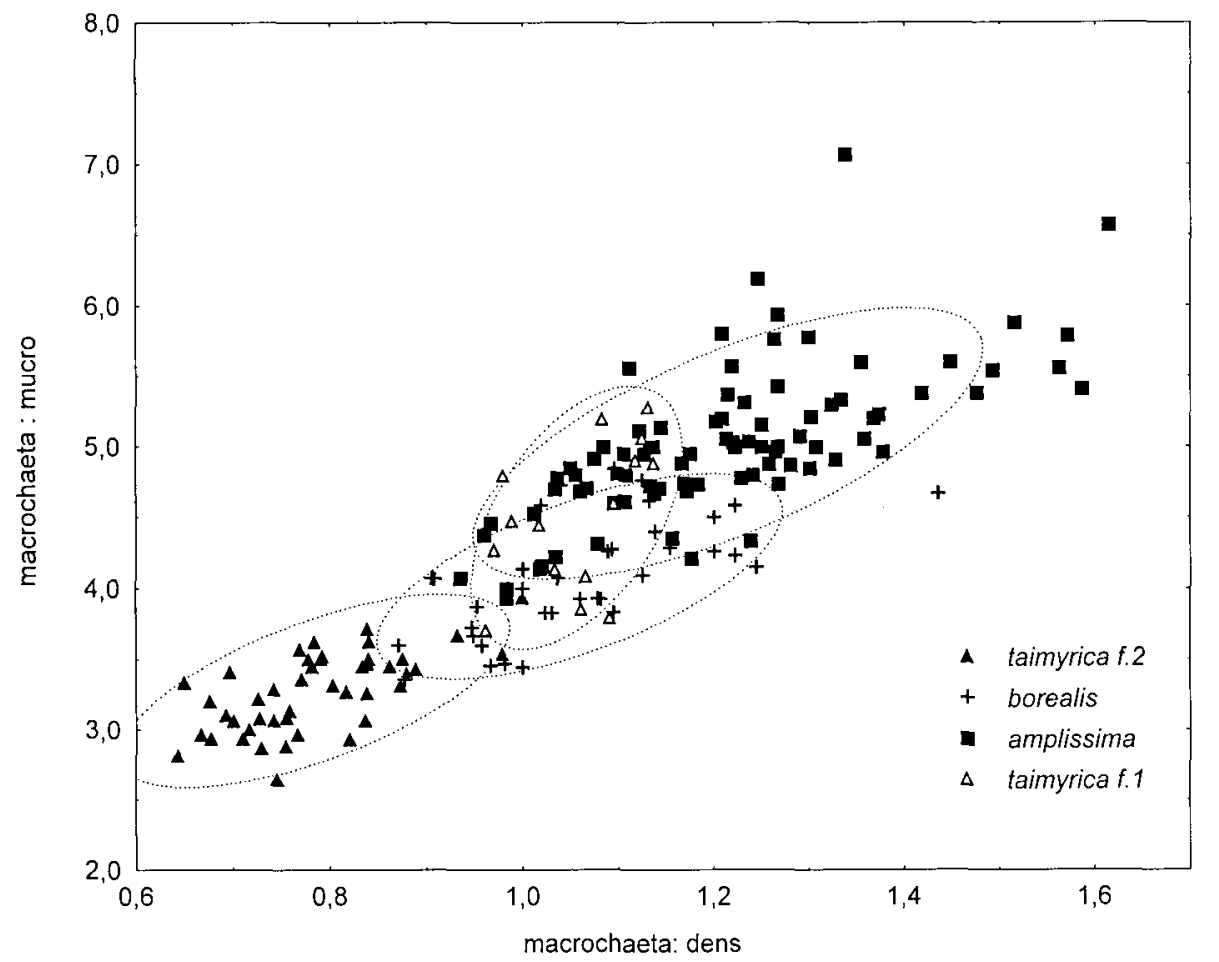

Fig. 24. The relative length of the macrochaetae on the end of abdomen in species of $F$. taimyrica complex.

coll. AB; Loc. 63, 2 ex., coll. MSPU; SOUTH: Loc. 72, 2 ex., coll. MSPU, Loc. 73, 10 ex., coll. MSPU; Loc. 74, 3 ex., coll. MSPU; Loc. 75, 10 ex., coll. MSPU.

Name derivation. It is a common species throughout the North Palaearctic, reflected by its specific name.

Affinities. A characteristic species due to the small size and specific pigmentation. It is very similar to $F$. sp. $n$. aff. palaearctica, having the same number of ommatidia and a similar chaetotaxy of furca (cf. Figs 31-36, 25-29). They can be distinguished by the following characters:

\begin{tabular}{lccccc}
\hline Species & $\begin{array}{c}\text { ms on } \\
\text { Th. III }\end{array}$ & $\begin{array}{c}\text { Upper } \\
\text { coxa of } \\
\text { leg II }\end{array}$ & $\begin{array}{c}\text { Anterior } \\
\text { furcal } \\
\text { subcoxa }\end{array}$ & $\begin{array}{c}\text { PAO/ } \\
\text { Ant. I } \\
\text { width }\end{array}$ & $\begin{array}{c}\text { Anterior } \\
\text { chaetae } \\
\text { on dens }\end{array}$ \\
\hline $\begin{array}{c}\text { F. sp.n. aff. } \\
\text { palaearctica }\end{array}$ & + & $3(2-4)$ & $5(4-6)$ & $1.6-1.9$ & 8 \\
\begin{tabular}{c} 
F. palaearctica \\
\hline
\end{tabular} & - & 1 & 3 & $1.0-1.2$ & 7 \\
\hline
\end{tabular}

Habitually it can be confused with pale specimens of $F$. manolachei, from which $F$. palaearctica differs by having only $1+1$ ommatidia, no basal $\mathrm{ms}$ on Ant. III, and a "corner" sensillum on Th. II always in front of the p-row.

Distribution. Finland, northern regions of European part of Russia and almost all Siberia. In Siberia it is one of the commonest species in both Arctic and boreal communities. Found also in Arctic Canada (Devon Isl.), but seems to be absent in Spitsbergen and in the easternmost parts of the Russian North (Wrangel Isl., Chukotka).

\section{Folsomia sp. n. aff. palaearctica}

Material. EUR: Loc. 24, 2 ex., coll. AB; Loc. 33, 14 ex., coll. AB; CSIB: Loc. 52, 13 ex., coll. AB; SOUTH: Loc. 74, 3 ex, coll. MSPU.
Affinities. The species is described in separate paper (Potapov \& Dunger, in press). It can be defined by: $1+1$ ommatidia, $1+1$ anterior chaetae on manubrium, very long postantennal organ (Fig. 26), ms on lateral part of Th. III present (Fig. 25), basal ms on Ant. III missing. The last character separates it from all the relatives $(F$. quadrioculata, $F$. taimyrica, etc.) except $F$. palaearctica. It can be distinguished from the $F$. taimyrica complex by the $2+2$ chaetae on the central part of posterior side of manubrium and $3+3$ lateral chaetae on ventral tube, and from $F$. quadrioculata and $F$. manolachei by the $1+1$ apical chaetae on posterior side of manubrium and only one ommatidium. Habitually $F$. sp. n. aff. palaearctica is rather similar to $F$. borealis, the smallest species of the $F$. taimyrica complex.

Distribution. Northern parts of the Russian Plain and some scattered records from the central (Putorana Plateau) and southern Siberia. It is known also from Mongolia.

\section{The $F$. regularis complex}

The morphology of the members of this complex is within the limits of the traditional understanding of $F$. regularis $(1+1$ ommatidia, from $2+2$ to $7+7$ (usually $3-5$ ) chaetae on the anterior side of manubrium). They are also characterized by a quadrioculata-like arrangement of sensilla, by the chaetotaxy of the posterior side of manubrium resembling that of the $F$. taimyrica complex (Fig. 39 ), and by the presence of a single lateral sensillum on Ant. III $(F$. regularis from Devon Isl. exceptionally show a variation in the latter character).

Below we fix the positions of $F$. regularis and $F$. ozeana, recover $F$. binoculata and describe a new species 


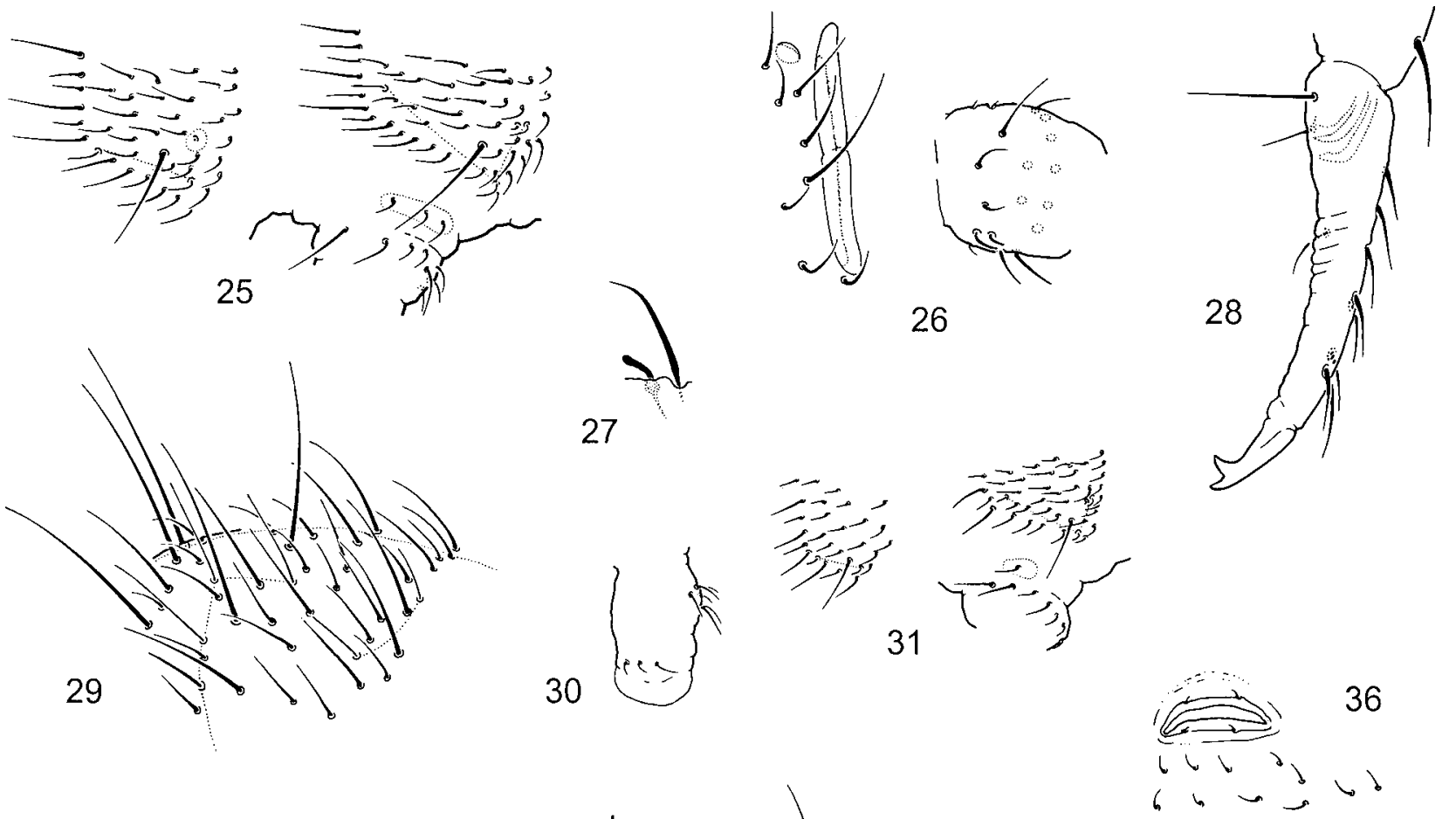

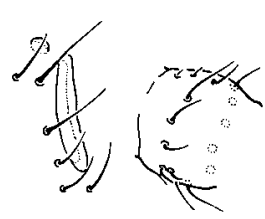

32

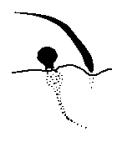

33

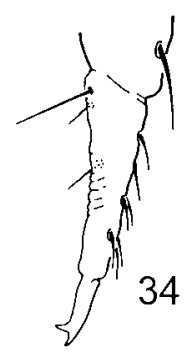

34
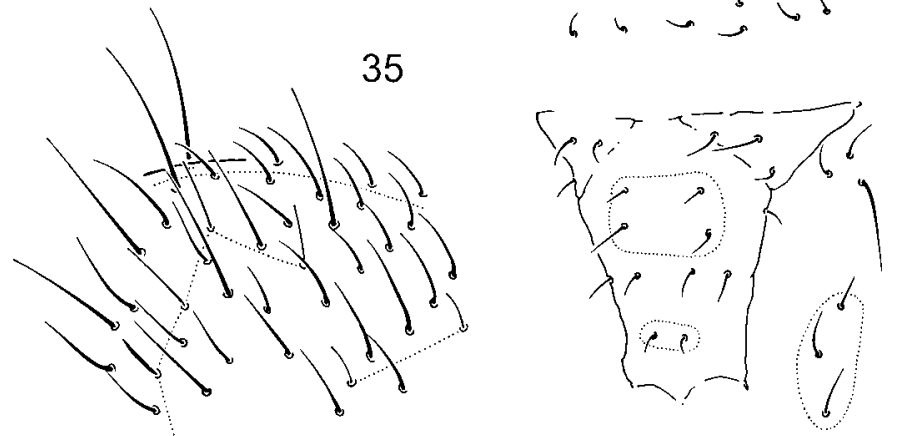

$26,28,29,32,34-36$

Figs 25-36. 25-29: F. sp. n. aff. palaearctica. 25 - lateral parts of Th. II-III; 26 - PAO, ommatidium and Ant. I; 27 - apical organite and microsensilla of Ant. IV; 28 - dens laterally; 29 -- chaetotaxy of the end of abdomen. 30-36: F. palaearctica sp. n. 30 ventral tube; 31 - lateral parts of Th. II-III; 32 - PAO, ommatidium and Ant. I; 33 - apical organite and microsensilla of Ant. IV; 34 - dens laterally; 35 - chaetotaxy of the end of abdomen; 36 - genital plate and furcal area. Scales: $27,33-0.01 \mathrm{~mm}, 25-26,28-32$, $34-36-0.05 \mathrm{~mm}$.

of the complex. All these species have previously been listed as $F$. regularis from different parts of the Holarctic.

\section{Folsomia regularis Hammer, 1953}

Material. AR: WRANG Loc. 20, 4 ex., coll. AB; NWT Loc. 22, 22 ex., coll. AB; Loc. 23, 14 ex, coll. AB.

Affinities. The species was described from Ellesmere Island (Arctic Canada) and subsequently recorded all over the Arctic and in more southerly regions (in East Asia as a senior synonym of $F$. ozeana). Our material from Ellesmere Island and Devon Island indicates the presence of $2+2$ macrochaetae on Th. III in Canadian specimens, whereas Palaearctic $F$. regularis always has only $1+1$ macrochaetae on Th. III (medial macrochaetae are not differentiated). Our new definition of the species considerably restricts its area of distribution. F. regularis s. str. can be characterised by two macrochaetae on each side of Th. III (Fig. 37 and 38) and 4+4 latero-distal chae- tae on ventral tube, white colour, and by the presence of a basal microsensillum on Ant. III.

Specimens of $F$. regularis from the Wrangel Isl. have slightly longer macrochaetae than Nearctic ones.

$F$. regularis is very similar to the northern European species $-F$. agrelli Gisin, 1944. The latter differs only in the lower number $(2+2)$ of anterior chaetae on the manubrium. Hammer (1954), however, indicated considerable variation of this character in F. regularis (from $2+2$ to $4+4$ ), which is in agreement with our material (Fig. 40). We have studied several specimens of $F$. agrelli from Norway (Oppland) and found a few specimens with an abnormal number $(3+2$ or $3+4)$ of anterior chaetae on the manubrium. Possibly, $F$. agrelli and $F$. regularis belong to the same variable species.

Distribution. F. regularis is mainly a Nearctic species with a single verified record for the East Palaearctic. All other records should be probably referred to $F$. binoculata, $F$. ozeana or $F$. atropolaris. 


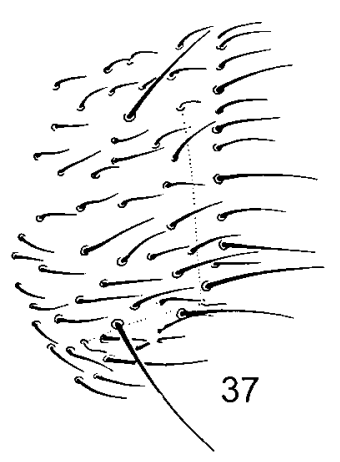

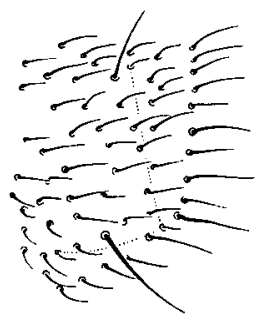

38

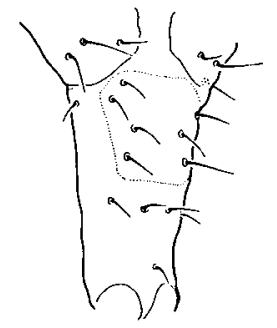

39

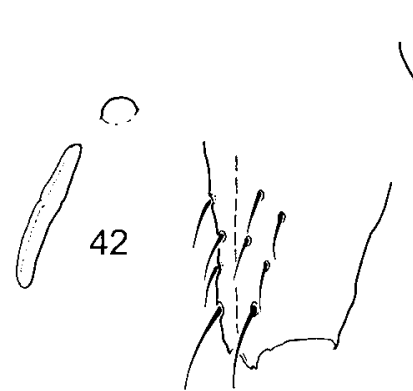

43

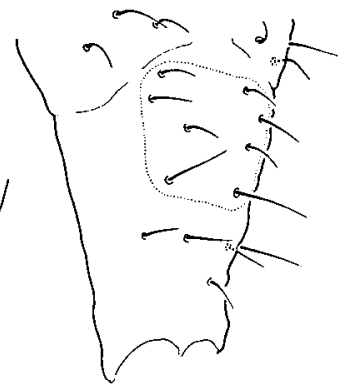

44
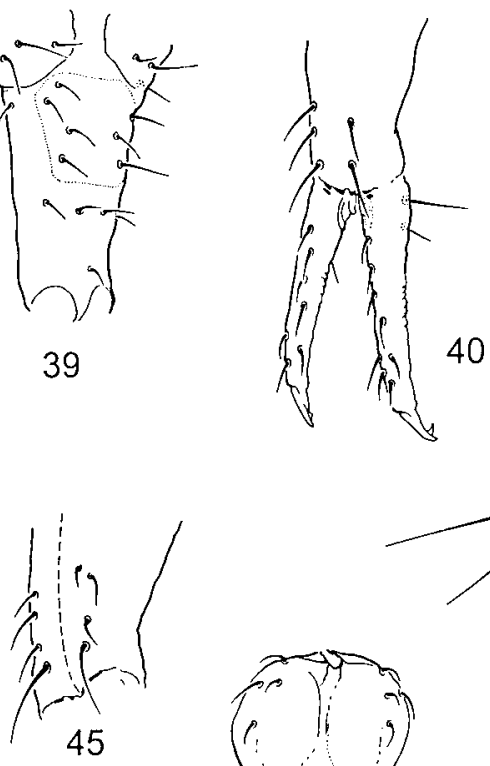

46
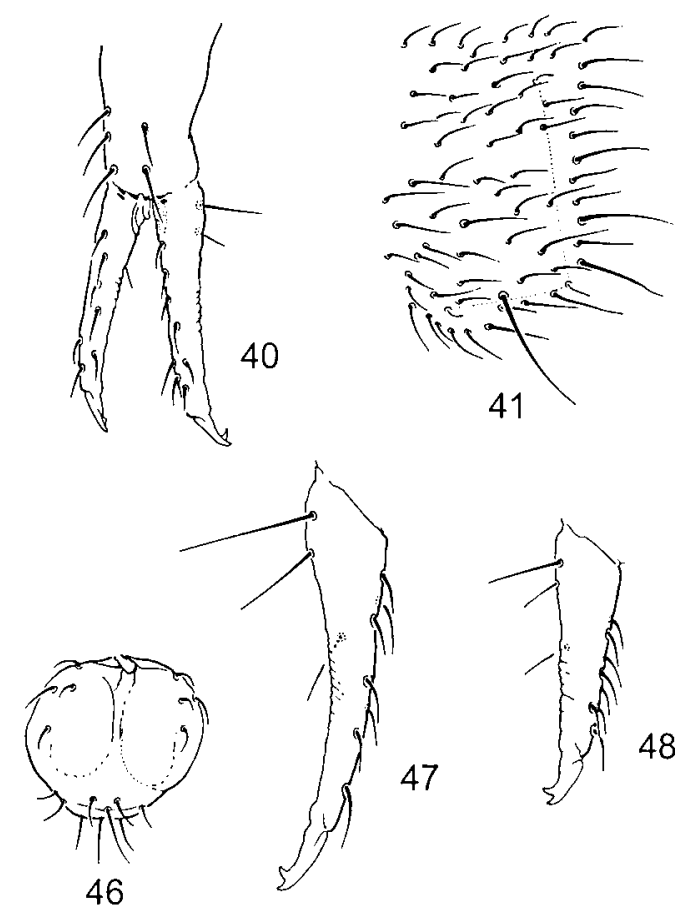
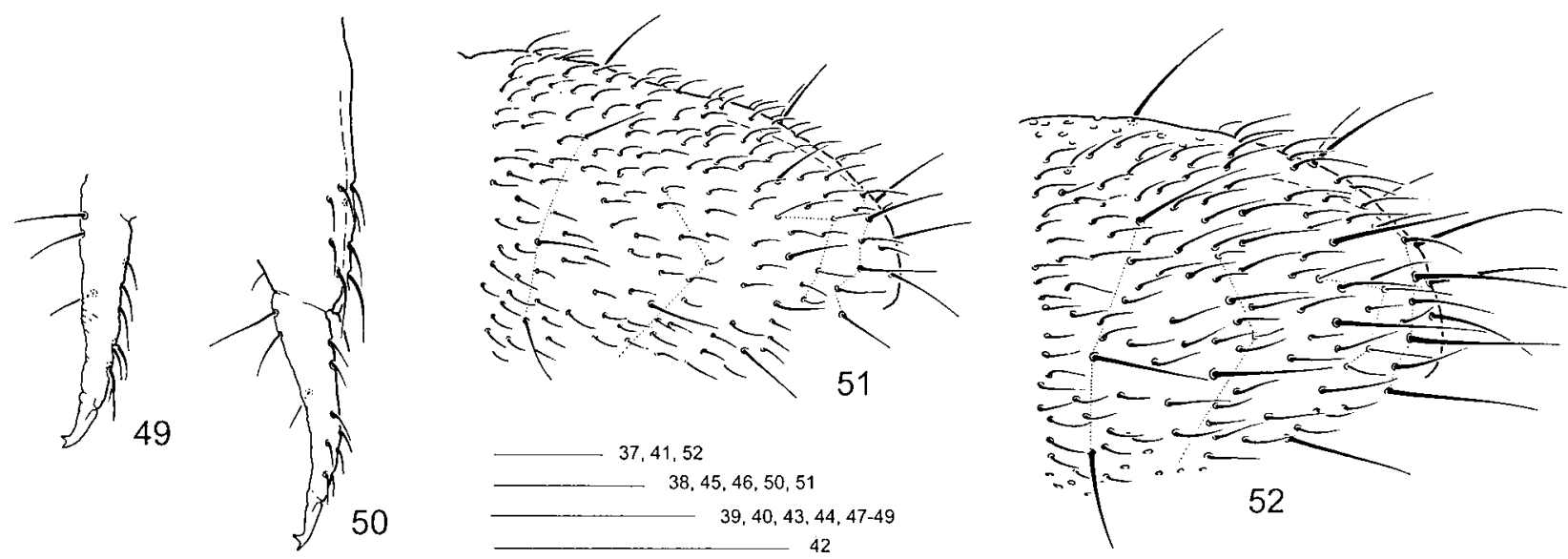

Figs 37-52. 37-40: F. regularis. 37 - lateral part of Th. III (Wrangel Isl.); 38 - dito (Devon Isl., NWT of Canada); 39 - manubrium posteriorly; 40 - furca anteriorly. $4 \mathrm{l}-52: F$. binoculata. 41 - lateral part of Th. III, form 2 (Severnaya Zemlya); 42 - PAO and ommatidium, form $2 ; 43$ - anterior side of manubrium, form 2;44 - posterior side of manubrium, form $2 ; 45$ - common variant of chaetotaxy of anterior side of manubrium, form 1 (Severnaya Zemlya); 46 - ventral tube, form 1; 47 - dens, form 1;48 - dtto, form 2 (Severnaya Zemlya); 49 - dtto, form 2 (Olenek Bay); 50 - furca laterally, form 1; 51 - dorsal chaetotaxy of Abd. IV-VI, form $2 ; 52$-dtto, form 1 . Scale: $0.1 \mathrm{~mm}$.

Folsomia binoculata (Wahlgren, 1899)

Isotoma binoculata Wahlgren, 1899.

Folsomia regularis auct. nec Hammer, 1953.

Redescription. Body length up to $1.7 \mathrm{~mm}$. From almost white to pale spotty grey. Large pigment grains, if present, form a special color pattern (Fig. 53). Eye region always pigmented. $1+1$ ommatidia, the corneas roundish and well distinguished. PAO narrow, clearly constricted in the middle, without inner "denticles", with 6-7 chactae along posterior edge (Fig. 42), distinctly longer than width of Ant. I. Maxillary palp bifurcate, outer maxillary lobe with 4 sublobal hairs.

Labral formula 4/5,5,4. Ventral side of head with $4+4-5+5$ chaetae along linea ventralis. Labium with $4+4$ chaetae. Ant. I, II, III with 3, 3, 1 microsensilla and 2, 1,
5 (2 inner, 2 outer and 1 latero-apical) sensilla, respectively.

Dorsal sensilla rather long, $2 / 3$ as long as common chaetae. Sensillar formula for Th. II-Abd. V: 4,3/2,2,2,3,5 (s), 1,0/1,0,0,0,0 (ms). Medial accp-sensilla on Th. II-Abd. III are in the middle parts of a segment, those on Abd. IV slightly in front of p-row of chaetae. Three medial sensilla on Abd. $V$ are 2-3 times as long as those on Abd. IV. Lateral sensillum shorter, not broad. Th. II-Abd. III with $1,1 / 3,3,3$ smooth macrochaetae. The largest macrochaetae of abdominal end 3.8-5.1 times longer than mucro. Thorax without ventral chaetae.

Claw toothless. Fore tibiotarsus with many additional chaetae. Upper and lower subcoxa of leg II with 3-4 and 6-9 chaetae, respectively. Retinaculum with $4+4$ teeth 


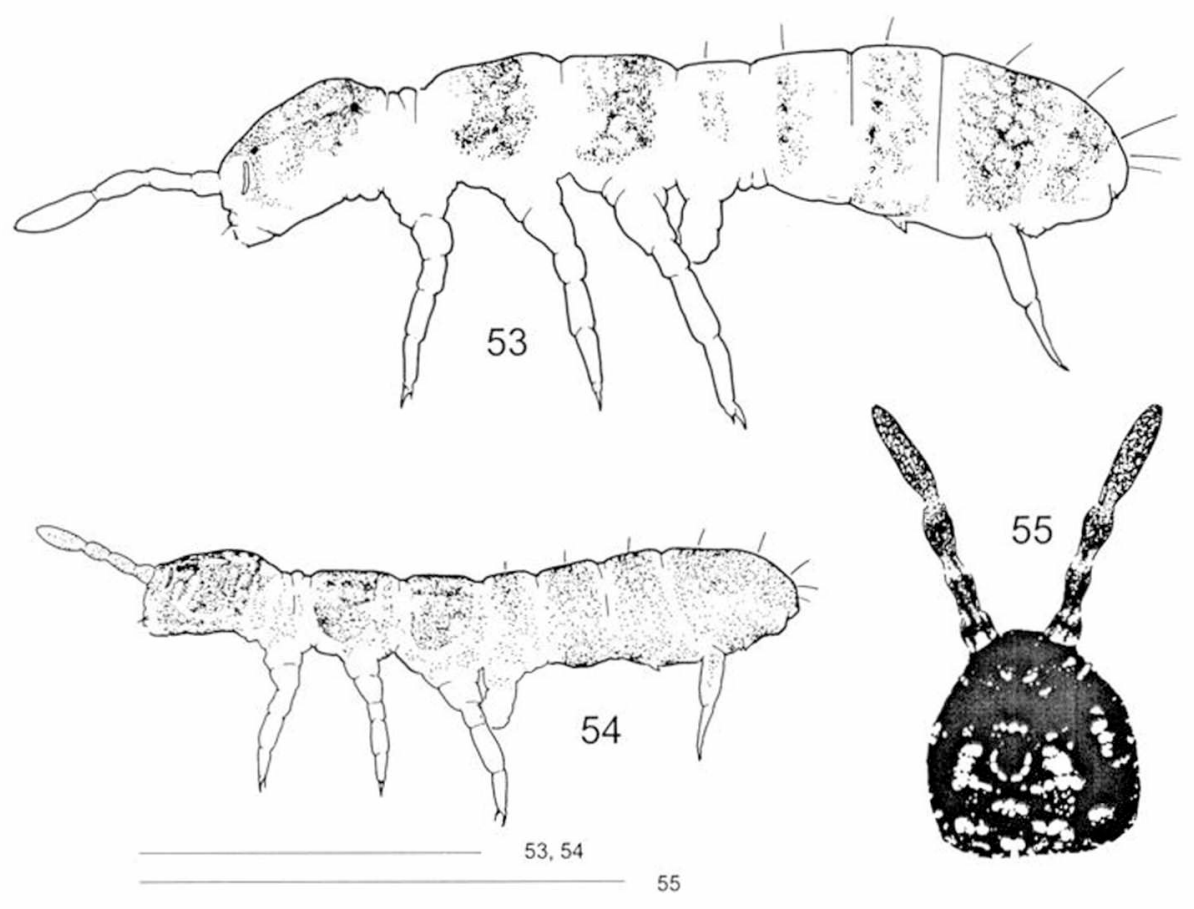

Figs 53-55. 53, 54: F. binoculata. 53 - habitus of dark-coloured specimen, form 1 (Olenek Bay); 54 - habitus of form 2 (Severnaya Zemlya). $55-F$. atropolaris sp. n., head in dark-coloured specimen. Scale: $0.5 \mathrm{~mm}$.

and one chaeta on corpus. Ventral tube with $4+4$ laterodistal chaetae and usually 7-9 (6-11) posterior ones (Fig. 46). Anterior furcal subcoxa with 6-8 chaetae, posterior one with 3-5 chaetae. Manubrium anteriorly with two longitudinal rows of mostly $3+4$ or $4+4$ chaetae, the total number varying between 5 and 10 (Figs 43, 45). Posterior side of manubrium with $3+3$ latero-basal, $4+4(3+3-5+5)$ central, 2+2 distal, and 1-2 apical chaetae (Fig. 44). Number of chaetae on lateral sides of manubrium varies from $0+0$ to $1+2$, often $1+0$. Dens crenulated, anteriorly with 7-8, posteriorly with 3 chaetae ( 2 basal and 1 in the middle part) (Figs 47-50). Mucro with two teeth.

Material. AR: SPITS Loc. 1, 28 ex., coll. MSPU; FJL Loc. 3-7, 139 ex., coll. MSPU; SEVZEM Loc. 10-12, 90 ex., coll. AB; NOVISL Loc. 13-15, 98 ex., coll. MSPU; Loc. 16-19, 31 ex., coll. AB; URAL: Loc. 38,2 ex., coll. MSPU. WSIB: Loc. 39, 6 ex., coll. AB; Loc. 40, 2 ex., coll. AB; CSIB: Loc. 47, 3 ex., coll. AB; Loc. 48,5 ex., coll. AB; Loc. 49,4 ex., coll. AB; Loc. 50,5 ex., coll. AB; Loc. 51, 1 ex., coll. AB; Loc. 54, 4 ex., coll. AB; NESIB: Loc. 56,1 ex., coll. AB; Loc. 58,4 ex., coll. MSPU; Loc. 61, 2 ex., coll. AB; Loc. 63, 5 ex., coll. MSPU; EAST: Loc. 65,4 ex., coll. MSPU.

Affinities. $F$. binoculata was considered as a "species dubia" for a long time because of a very short PAO figured by Wahlgren (only two times longer than an ommatidium). As the drawings of this author were rather schematic it can be supposed that a figure for $F$. binoculata was not fully correct. $F$. binoculata was originally described from Spitsbergen and Fjellberg (1994) already mentioned that it is a probable synonym of $F$. regularis the only Folsomia species with $1+1$ coloured ommatidia found there. We prefer to treat both of them as separate species as our material from Hornsund (southern Spitsbergen) indicates some differences between Canadian and
Spitsbergen specimens which can be easily distinguished by the presence ( $F$. regularis) or the absence ( $F$. binoculata) of medial macrochaetae on Th. III (cf. Figs 37 and 41).

Variability. The above redescription is based mainly on the largest form of this species (form 1). It frequently occurs together with another form, which is even more numerous and common for the Russian North. These specimens (form 2) are distinctly smaller $(0.8-1.0 \mathrm{~mm})$, with darker and diffuse pigmentation (Fig. 54), and their macrochaetae are shorter, 2.7-3.9 times as long as mucro (cf. Figs 51 and 52). As a rule, manubrium bears more anterior chaetae, usually $4+4-5+5$, the posterior side of the ventral tube usually has a smaller number of chaetae (5-7). However, the variability of the characters overlaps.

The two forms can easily be distinguished in mixed populations by coloration and body size. Their status and relationships call for further investigation. Both of them are referred as $F$. binoculata here.

Distribution. Widely distributed all over the Arctic.

$F$. binoculata f. 1 has been recorded in various polar desert and Arctic tundra communities on the High Arctic archipelagos, found also in the northern Taimyr.

$F$. binoculata f. 2 is more common and widespread in the Russian Arctic (from Franz Josef Land to Chukotka). Inhabits all the tundra subzones penetrating into the polar deserts as well. The most inland record: alpine zone of Verkhoyansky Mt. Range. No records from Spitsbergen and Wrangel Island.

\section{Folsomia atropolaris sp. n.}

Description. Body length $1.0-1.4 \mathrm{~mm}$. From mottled grey to black (Fig. 55), pigment grains form irregular spots on the body. Habitually similar to dark-coloured 

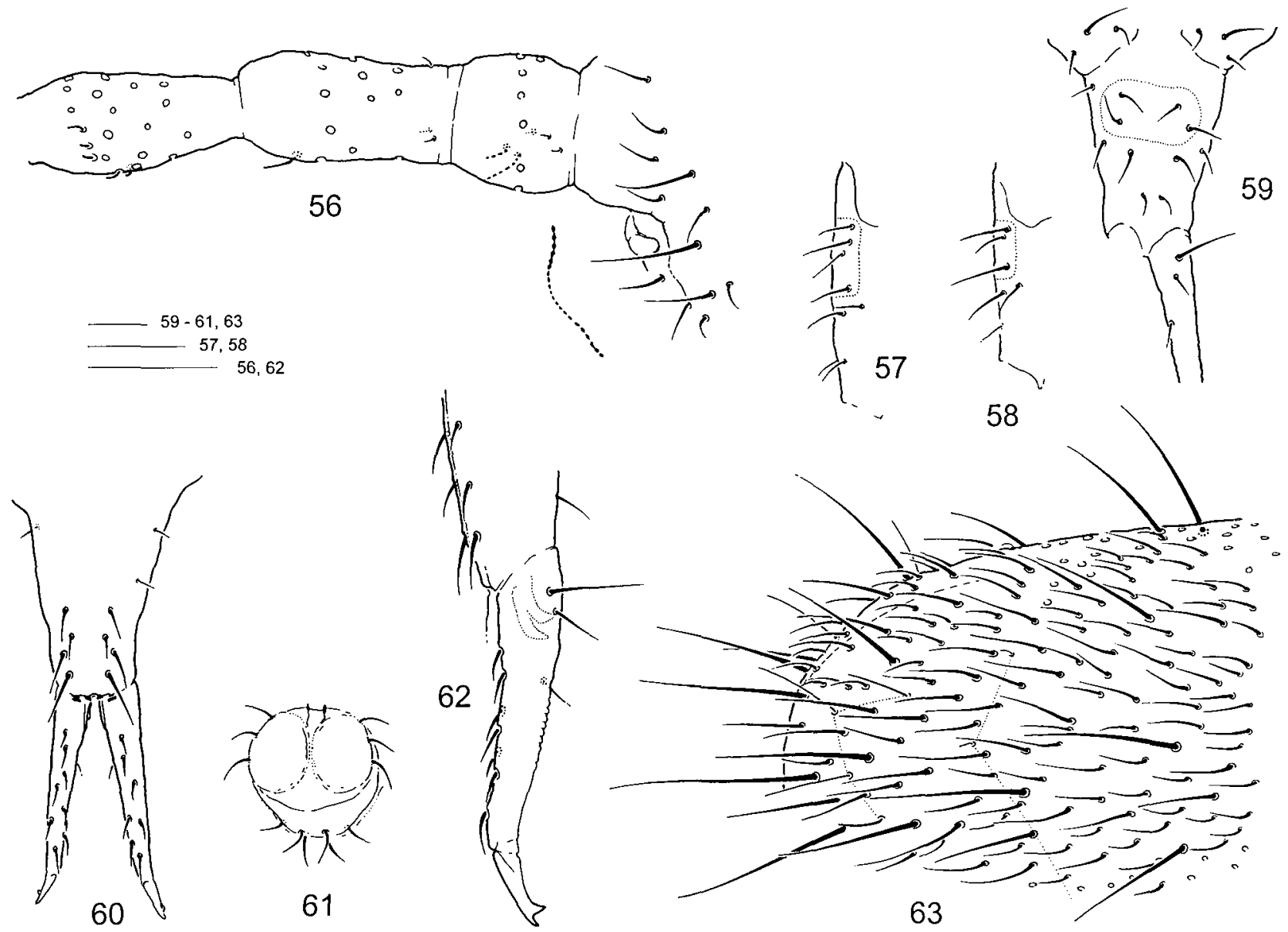

Figs 56-63: Folsomia atropolaris sp. n. 56 - Ant. I-Ill (only sensilla and microsensilla shown) and ommatidium region; 57, $58-$ posterior side of manubrium from lateral position (variation, Taimyr Lake); 59 - furca from posterior view (Wrangel Isl.); 60 - anterior side of furca; 61 - ventral tube; 62 - distal part of manubrium and dens (laterally, another specimen); 63 - dorsal chaetotaxy of Abd. IV-VI. Scale: $0.05 \mathrm{~mm}$.

specimens of $F$. quadrioculata. The $1+1$ ommatidia are indicated by pigment concentration. The corneas, however, are hardly distinguished and look like swellings of the integument surface. PAO narrow, clearly constricted at the middle, usually with inner "denticles", with 6-7 chaetae along posterior edge, distinctly longer than width of Ant. I. Maxillary palp bifurcate, outer maxillary lobe with 4 sublobal hairs.

Labral formula $4 / 5,5,4$. Ventral side of head with $4+4(5+5)$ chaetae along linea ventralis. Labium with $4+4$ chaetae. Ant. I, II, III with 3, 3, 0 microsensilla and 2, 1, 5 (2 inner, 2 outer and 1 latero-apical) sensilla respectively (Fig. 56).

Body sensilla short. Sensillar formula for Th. II-Abd. V: 4,3/2,2,2,3,5 (s), 1,0/1,0,0,0,0 (ms). Medial accpsensilla on Th. II-Abd. III are situated in the middle part of segments, those on Abd. IV slightly in front of p-row of chaetae. On Abd. V the three medial sensilla about 4 times longer than those on Abd. IV (Fig. 63). Lateral sensillum shorter, rather thin. Macrochaetotaxy is typical for the genus: $1,1 / 3,3,3$. The largest macrochaetae of the abdominal tip are $3.3-4.4$ times longer than mucro. Axial chaetom of Th. II-Abd. III: 9-11,7-8/4-5,4-5,4-5. Thorax without ventral chaetae.

Claw toothless. Tibiotarsus of leg I with 26-29 chaetae. Upper and lower subcoxa with 2-4 and 7-10 (leg II), 5-7 and 8-10 (leg III) chaetae respectively. Retinaculum with $4+4$ teeth and one chaeta on corpus. Ventral tube with $3+3$ latero-distal chaetae and 6-8 posterior ones (Fig. 61). Anterior furcal subcoxa with 6-9 chaetae, posterior one usually with 3 chaetae. Manubrium anteriorly with two longitudinal rows of chaetae, mostly $4+4$ or $3+4$ (Figs 60 , 62 ), variants with $3+3$ and $6+5$ chaetae were also found Posterior side of manubrium with $3+3$ latero-basal, $2+2-4+4$ (see variability below) central, $2+2$ distal, and 2 (rarely 3) apical chaetae (Fig. 59). In addition, there are $1+1$ (rarely $0+0$ or $2+1$ ) chaetae on lateral sides of manubrium. Dens crenulated, anteriorly with $7-8$, posteriorly with 3 chaetae ( 2 basal and 1 in the middle part). Mucro with two teeth.

Type material. Holotype: \& (slide), labelled "Russia, Wrangel Isl., Mamontovaya River $\left(70^{\circ} 59^{\prime} \mathrm{N}, 179^{\circ} 35^{\prime} \mathrm{E}\right)$, Dryas association on stony outcrop, 23.-24.vii.1994", leg. A. Babenko, coll. MSPU. Paratypes: 3 specimens from the holotype sample; 5 specimens from the same region and date but 
"under Saxifraga firma cushion on the summit of Matyushkin Mt., alt. $662 \mathrm{~m}$ ", leg. A. Babenko, coll. MSPU.

Additional material. WSIB: Loc. 39, 3 ex., coll. AB; CSIB: Loc. 47, 16 ex., coll. AB; NESIB: Loc. 56, 10 ex., coll. AB; Loc. 58,3 ex., coll. MSPU.

Name derivation. The name reflects the colour and the distribution of the species.

Affinities. As a member of $F$. regularis complex, $F$. atropolaris is characterized by $1+1$ ommatidia and the usual number of anterior chaetae on manubrium and dens, but can easily be distinguished by its dark colour, shorter dorsal sensilla on the terga and by the absence of a basal microsensillum on Ant. III. Weak differentiation of cornea is also characteristic. It also differs from $F$. regularis and $F$. binoculata by having only $3+3$ latero-distal chaetae on the ventral tube.

Variability. The number of chaetae in the central part of posterior side of manubrium varies from $2+2$ (Wrangel, Verkhoyansky Range, Yamal) to $3+3-4+4$ (Yana, Taimyr) (Figs 57-59).

Distribution. Scattered records from the northern regions of Siberia, where the Yamal Peninsula is the westernmost point of its distribution.

\section{Folsomia sp. aff. ozeana Yosii, 1954}

Material. CSIB: Loc. 47, 25 ex., coll. AB; Loc. 54, 2 ex., coll. AB; AR: NOVISL Loc. 13, II ex., coll. AB; WRANG Loc. 20, 36 ex., coll. AB; Loc. 21, 4 ex., coll. MSPU; NESIB: Loc. 56,7 ex., coll. AB; Loc. 60,69 ex., coll. MSPU; Loc. 61, 7 ex., coll. AB.

Affinities. F. ozeana was recorded from the Far East of Russia, Japan, Korea, East China, USA. Later Yosii (1969) synonymized it with $F$. regularis. However our material from almost the same region (Sakhalin and Kurile Islands) clearly differs from both $F$. regularis and $F$. binoculata by having $3+3$ latero-distal chaetae on the ventral tube. Besides, F. ozeana, contrary to F. regularis, is characterized by having only one macrochaeta on Th. III.

Specimens from the northern areas differ from the main form by smaller size and shorter macrochaetae. The ratio of the largest abdominal macrochaetae : mucro is 3.8-4.9 in the main form of F. ozeana (Kurile Islands), whereas it is only 2.1-3.4 in the northern form (Wrangel Island). As no other differences are observed, the status of this northern form remains unclear pending further investigation. As a whole, it is very similar to $F$. binoculata $\mathrm{f}$. 2 but has only $3+3$ latero-distal chaetae on the ventral tube. In a mixed population they can be separated by body colour: grey in F. binoculata f. 2, and yellowish-white in Folsomia sp. aff. ozeana.

Distribution. Widespread in the eastern part of the Russian Arctic (from Taimyr to Wrangel Isl.). Most records are from the tundra zone, but found also in taiga.

\section{The $F$. sexoculata complex}

Five species which can be considered as representatives of this group have been found in our northern material. Very short dorsal chaetae and a particular arrangement of sensilla [Ant. I always with 3 sensilla (Fig. 65), medial sensillum on Abd. II-III is between Mac2 and Mac3, that on Abd. IV situated in anterior part of the tergum] is characteristic of all of them.

\section{Folsomia sexoculata (Tullbẹg, 1871)}

Material. EUR: Loc. 26, 4 ex., coll. MSPU; Loc. 27, 125 ex., coll. MSPU; Loc. 28, 10 ex., coll. MSPU; Loc. 29, 2 ex., coll. MSPU; Loc. 34, 5 ex., coll. AB; WSIB: Loc. 40, 1 ex., coll. AB; CSIB: Loc. 46, 1 ex., coll. AB; Loc. 48, 68 ex., coll. AB.

Affinities. The species differs from the other northern members of the group in $3+3$ ommatidia and more chaetae on posterior side of furca, namely basal part of dens with 4 chaetae, central part of manubrium at least with $10+10$ (usually more) chaetae. In adult specimens of $F$. sexoculata the anterior side of manubrium usually bears $2+2$ distal chaetae and $1+1$ additional chaetae at a distance.

Distribution. For the time the west of Taimyr Peninsula is the easternmost record of this species. It lives along the sea coast or banks of lakes and streams met with river deltas.

\section{Folsomia diplophthalma (Axelson, 1902)}

Material. EUR: Loc. 27, 67 ex., coll. MSPU; Loc. 28, 2 ex., coll. MSPU; Loc. 31, 3 ex., coll. MSPU; CSIB: Loc. 44, 6 ex., coll. MSPU; Loc. 46, 51 ex., coll. AB; Loc. 48, 9 ex., coll. AB; Loc. 52, 12 ex., coll. AB; NESIB: Loc. 56, 6 ex., coll. AB.

Affinities. We accept here a new understanding of this species based on holotype examination (Potapov \& Dunger, in press). Accordingly $F$. diplophthalma can be characterised by $1+1$ ommatidia (Fig. 75 ), normally $4+4$ chaetae on anterior side of manubrium, 14-17 anterior chaetae on dens and sexoculata-like arrangement of sensilla.

Distribution. Probably widespread in the northern regions of the European part of Russia and Siberia: recorded from Karelia to Yana Delta. In the Arctic it prefers sites enriched with organic material (debris in the supralittoral, mammal nests), southwards it was also recorded in litter from damp woods. All previous records of $F$. diplophthalma should be verified.

\section{Folsomia cf. diplophthalma (Axelson, 1902)}

Affinities. This form is very similar to the previous species but differs in having more anterior chaetae on the manubrium (from $7+7$ to $9+9$ ) and less chaetae (9-12) on the anterior furcal subcoxa. Its species status is doubtful.

Distribution. A single record from a south slope meadow in western Taimyr.

\section{Folsomia microchaeta Agrell, 1939}

Material. EUR: Loc. 33, 1 ex., coll. AB; AR: NOVZEM Loc. 9, 65 ex., coll. AB; WSIB: Loc. 40, 3 ex., coll. AB; CSIB: Loc. 51, 2 ex., coll. AB; NESIB: Loc. 58, 6 ex., coll. MSPU; Loc. 60, 2 ex., coll. MSPU.

Affinities. Well distinguished species because of the two contrasting large black eye spots on each side of head (Fig. 73), but specimens with reduced or absent eye pigment are rather common in some populations. The anterior chaetotaxy of the manubrium (adults) varies from $2+2$ to $3+3$. The variant with $2+2$ chaetae is not very common, but specimens with $3+2$ chaetae occur with the 

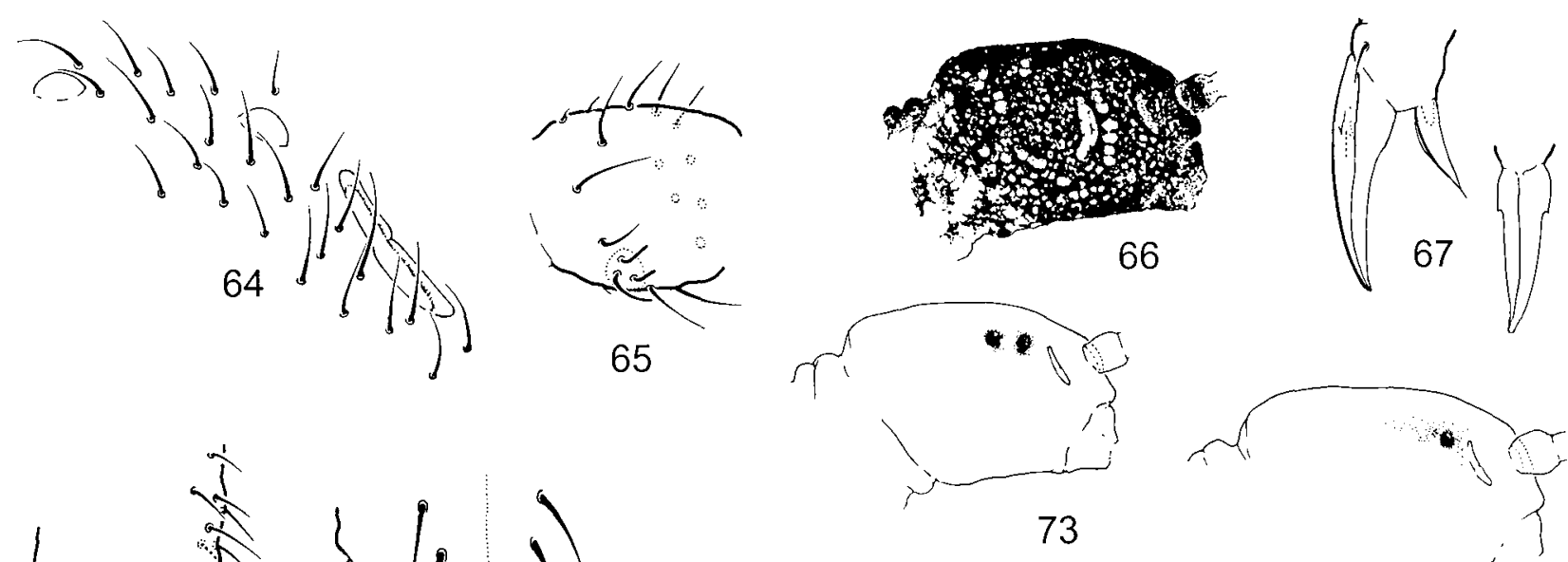

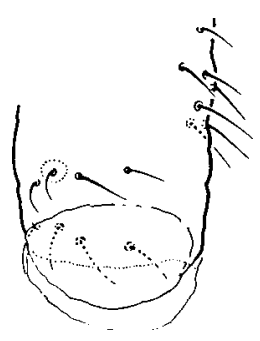

68
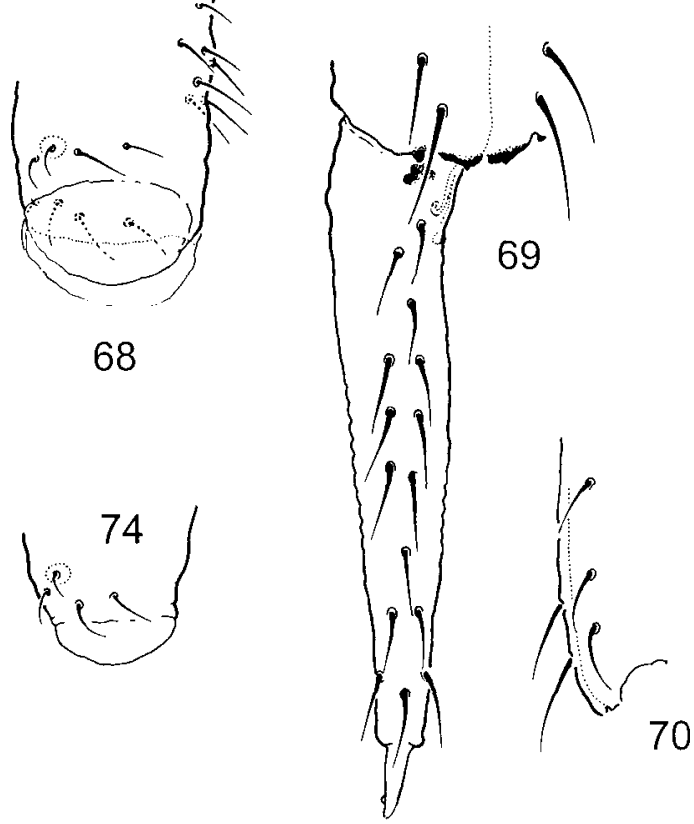

73

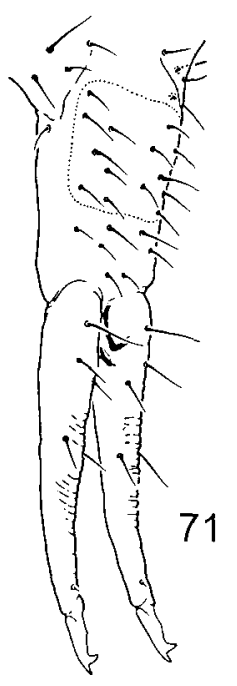

75

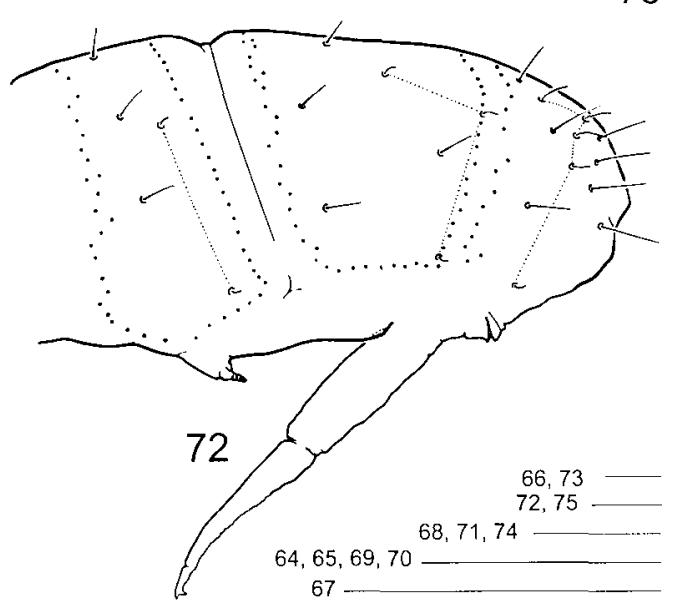

Figs 64-75. 64-72: F. sp. aff. altamontana. 64 - PAO, ommatidium; 65 - Ant. I; 66 - color pattern on head; 67 - claw III (lateral side) and claw II (inner side); 68 - ventral tube; 69 - anterior side of furca; 70 - anterior side of manubrium (another specimen); 71 - posterior side of furca; 72 - chaetotaxy of Abd. III-VI (sensilla connected). 73-74: F. microchaeta. 73 - color pattern; 74 - ventral tube. $75-F$. diplophthalma, color pattern. Scale: $0.05 \mathrm{~mm}$.

same frequency as $3+3$. F. microchaeta can easily be distinguished from $F$. diplophthalma and associated species by the $2+2$ equally large ommatidia and few chaetae on the manubrium. They can also be separated by the length of the sensilla on Th. II: contrary to $F$. diplophthalma and $F$. similis, the sensillum near the hind corner of the segment is always slightly shorter than the common chaetae in F. microchaeta (cf. Figs 77 and 78).

Distribution. Probably widespread in the Arctic and mountainous regions of Russia, recorded from Kolguev Isl. to Yakutia. Rather rare species, indicated only from nival slopes and tundra sites.

\section{Folsomia sp. aff. altamontana Yosii,1971}

Description. With the characters of the sexoculatagroup. Body length from 1.0 to $1.6 \mathrm{~mm}$. Dark grey to black (colour pattern on head in one of the darkest specimens as in Fig. 66). 2+2 large ommatidia (Fig. 64). Ant. I with 3 sensilla (Fig. 65). Body sensilla slightly shorter than common chaetae (Fig. 72). Macrochaetae short, the largest ones of the last abdominal segments 1.8-2.4 times longer than mucro. Claw with small lateral teeth (Fig. 67).
Ventral tube with $4+4$ latero-distal chaetae. Manubrium usually with $2+2$ or $2+3$ anterior chaetae, sometimes more (up to $3+3$ and 2+4) (Figs 69, 70). Posterior side of manubrium with $4+4-4+5$ latero-basal, 7-9+7-9 central, 3+3 distal, and 2 apical chaetae (Fig. 71). Dens with 14-16 anterior chaetae, its posterior side with 3 basal chaetae, 2 chaetae in the middle part, and a tiny apical chaeta.

Material. AR: SEVZEM Loc. 10, 1 ex., coll. MSPU; Loc. 11, 26 ex., coll. MSPU; NOVISL Loc. 18, 9 ex., coll. AB; CSIB: Loc. 52, 750-900 m alt., 39 ex., coll. AB.

Affinities. This form is in good agreement with the original description of $F$. altamontana, found in alpine and nival communities (over $4,300 \mathrm{~m}$ alt.) of the Himalaya (Nepal). There are also some minor dissimilarities, viz. Yosii's specimens are smaller $(1.0 \mathrm{~mm})$ and always have $2+2$ anterior chaetae on manubrium and no minute apical chaeta on posterior side of dens (the latter can be easily overlooked). The status of our form can be cleared up only after modern redescription of $F$. altamontana.

On the other hand, the only distinct difference between $F$. sp. aff. altamontana and F. microchacta is their coloration. Other subtle differences are as follows: sensillum 


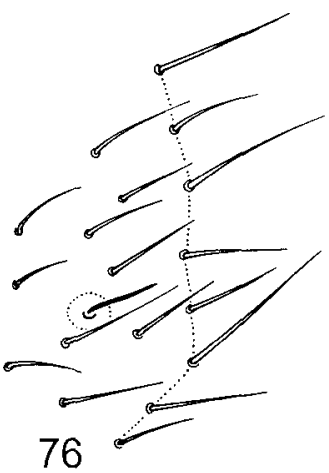

76

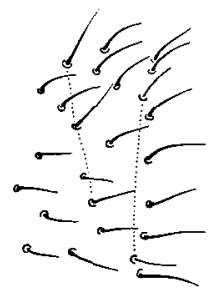

80

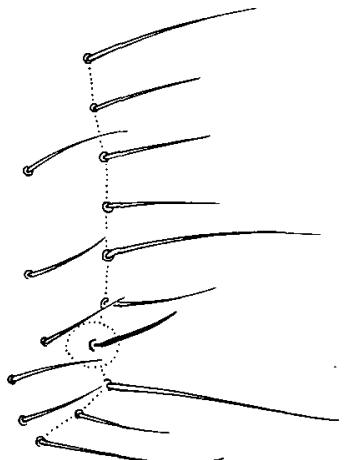

77
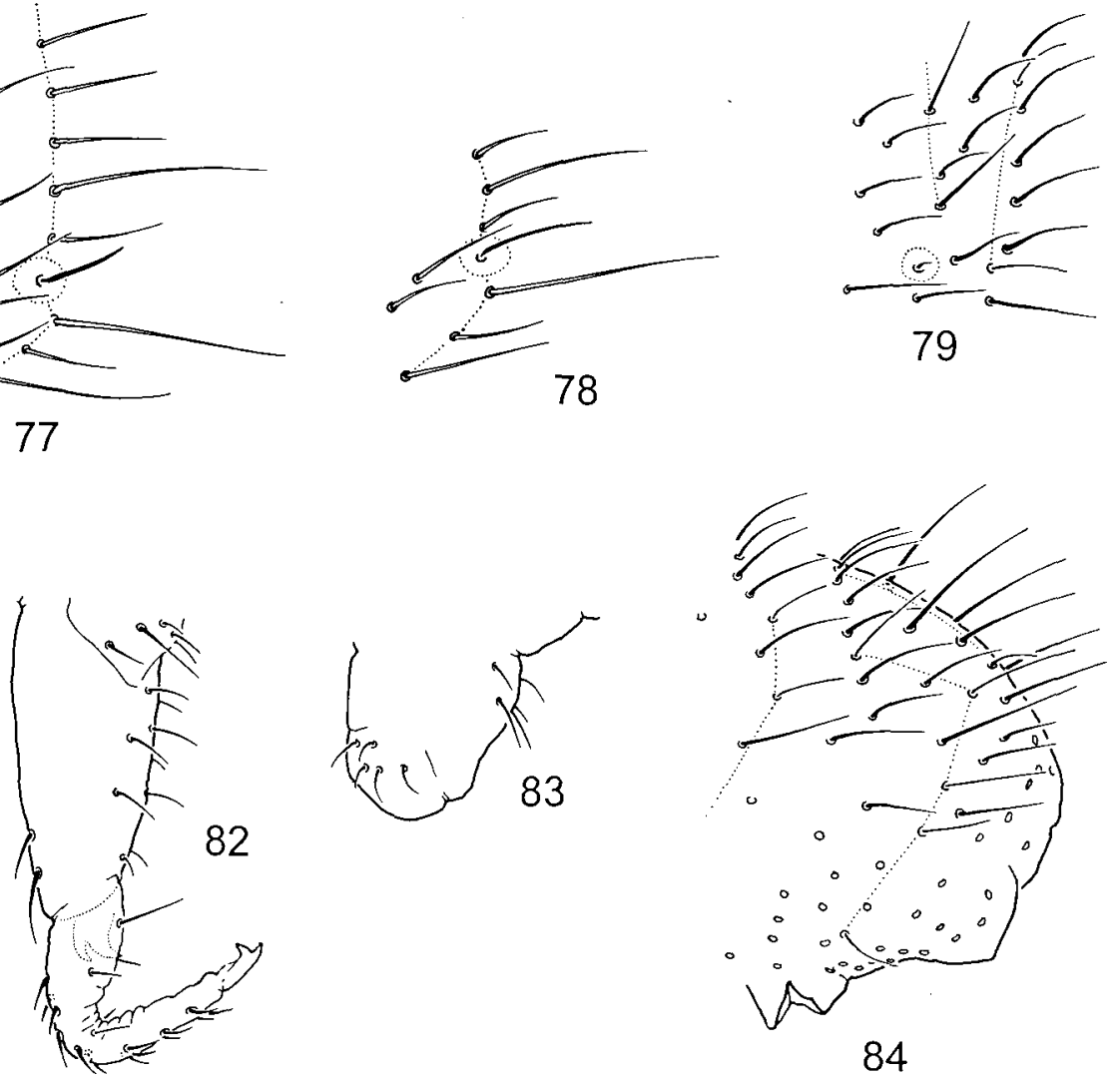

Figs 76-84. $76-F$. sp. aff. altamontana, chaetotaxy of posterior comer of Th. II. $77-F$. microchaeta, dtto. $78-F$. diplophthalma, dtto. 79 - F. bisetosa, lateral part of Abd. I. 80-84: F. cryptophila sp. n. 80 - lateral part of Abd. I; 81 - PAO; 82 furca laterally; 83 - ventral tube; 84 - chaetotaxy of the abdominal end. Scale: $0.05 \mathrm{~mm}$.

near hind corner of Th. II is within ( $F$. microchaeta) or in front of $(F$. aff. altamontana) the p-row of chaetae (Figs $77,76)$, the second lateral chaeta on the ventral tube is out of (F. microchaeta) (Fig. 74) or in a line with the other chaetae ( $F$. aff. altamontana) (Fig. 68).

Distribution. Arctic and nival communities of central Siberia.

\section{The $F$. fimetaria complex}

This group includes species without broad sensilla on abdomen, the sensilla on the abdominal terga are within the p-row, and ventral chaetae on Th. III are usually missing. Five species of the complex have been recorded in the northern regions of Russia.

Folsomia fimetaria (L., 1758)

A single record from northern Ural (Loc. 37, 1 ex., coll. MSPU).

Folsomia ciliata Babenko \& Bulavintsev, 1993

Material. EUR: Loc. 34, 3 ex., coll. AB; AR: NOVZEM Loc. 8, 2 ex., coll. MSPU; WSIB: Loc. 39, 1 ex., coll. AB; Loc. 42, 1 ex., coll. MSPU; CSIB: Loc. 47, 2 ex., coll. AB; Loc. 48, 67 ex., coll. AB.

Affinities. Inside the northern areas the species is well distinguished from the other Folsomia by having long, ciliate macrochaetae and a fimetaria-like arrangement of sensilla on the body. F. nivalis is very similar to this spe- cies but has more chaetae on anterior side of manubrium and is distributed only in the eastern part of the Palaearctic.

Distribution. Common in the tundra zone from Pechora Bay to Taimyr Peninsula.

Folsomia nivalis (Packard, 1873)

Material. EAST: Loc. 63, 3 ex., coll. MSPU.

Affinities. The specimens from our material are in agreement with the morphological description of Christiansen \& Bellinger (1980).

Distribution. Widespread in the Nearctic (Christiansen \& Bellinger, 1980). Common also in the castern Palaearctic (Kamchatka, Kurile Islands), the northernmost record is from the upper stretches of Kolyma River (northern taiga).

Folsomia sparsosetosa Stebaeva \& Potapov, 1997

Material. WSIB: Loc. 44, 1 ex., coll. MSPU; NESIB: Loc. 60, 56 ex., coll. MSPU.

Affinities. It can be easily separated from the closely related species ( $F$. ciliata, $F$. nivalis) by many anterior chaetae on manubrium (11-15), 4 basal chaetae on posterior side of dens, and sensilla situated in front of the $\mathrm{p}$ row of chaetae on Th. II-III. 
Distribution. Described from floodlands of the southern Siberia. The most northern records are from the northern taiga.

\section{Folsomia bisetosa Gisin, 1953}

Material. AR: SPITS Loc. 1, 93 ex., coll. MSPU; Loc. 2, 2 ex., coll. MSPU; NOVZEM Loc. 8, 13 ex., coll. MSPU; WRANG Loc. 20, 17 ex., coll. AB; NWT Loc. 22, 15 ex., coll. AB; EUR: Loc. 30,3 ex., coll. MSPU; Loc. 33, 2 ex., coll. AB; Loc. 34, 1 ex., coll. AB; URAL: Loc. 38, 1 ex., coll. MSPU; WSIB: Loc. 39, 13 ex., coll. AB; CSIB: Loc. 46, 56 ex., coll. AB; Loc. 47, 34 ex., coll. AB; Loc. 52, 11 ex., coll. AB; Loc. 54, 1 ex., coll. AB; Loc. 55, 4 ex., coll. MSPU; NESIB: Loc. 56, 4 ex., coll. AB; Loc. 60, 11 ex., coll. MSPU; Loc. 61, 11 ex., coll. AB; Loc. 63, 2 ex., coll. MSPU.

Affinities. A well defined species due to the few chaetae $(2+2)$ on anterior side of the manubrium which is rare in the $F$. fimetaria complex. The number of anterior chaetae on the dens is rather variable, ranging from 12 to 19 , usually $13-15$. Specimens with asymmetric arrangement, e.g. $12+15,13+18$, are also common.

Distribution. The species was described from Jan Mayen and has been recorded from all over the Arctic (circumpolar). In real tundra it usually prefers the warmest and richest biotopes, southwards it can be found only in bogs and other damp sites.

\section{Folsomia cryptophila sp. n.}

Description. Body length $0.5-0.6 \mathrm{~mm}$. Habitually it resembles small specimens of $F$. bisetosa. No ommatidia and pigment. PAO slightly longer than width of Ant. I, twice as long as claw, constriction and "denticles" absent (Fig. 81). Maxillary palp bifurcated, outer maxillary lobe with 4 sublobal hairs.

Labral formula $2 / 5,5,4$. Ventral side of head with $4+4$ chaetae along linea ventralis, labium with $4+4$ chaetae. Ant. I, II, III with 2, 3, 0 microsensilla and 2, 1, 5 sensilla, respectively.

Body sensilla almost as long as normal chaetae. Sensillar formula for Th. II-Abd. V: 4,3/2,2,2,3,5 (s), $1,0 / 0,0,0,0,0$ (ms). Medial accp-sensilla on Th. II-Abd. V are situated in the p-row. Sensorial set of Abd. V is common for the group (Fig. 84). Macrochaetae short and hardly differentiated, $1,1 / 3,3,3$ in number on Th. II-Abd. III. Th. III with about 17 chaetae in the p-row. The longest macrochaetae of the abdominal tip are 2.1-2.8 times longer than mucro. Thorax without ventral chaetae.

Claw toothless. Upper subcoxa of leg II-III with 1 and 3-4 chaetae, respectively. Retinaculum with $4+4$ teeth and one chaeta on corpus. Ventral tube with $4+4$ (rarely $5+5$ ) latero-distal chaetae and 4-5 posterior ones (Fig. 83). Manubrium anteriorly with $2+2$ chaetae arranged in longitudinal lines (Fig. 82). Dens crenulated, with 12-14 anterior chaetae, posteriorly with 3 basal chaetae and 2 chaetae in the middle part. Mucro bidentate. Ratio manubrium : dens : mucro as $4.9-5.2: 4.7-5.3: 1$.

Type material. Holotype: $\subsetneq$ (slide), labelled "West Taimyr, Ragosinka River, polar fox burrow, 19.vii.1983". A. Babenko leg., coll. MSPU. Paratypes: 20 specimens from the same locality.
Name derivation. Named after type habitat (crypta - covered passage in Latin).

Affinities. The new species differs from $F$. bisetosa by the presence of only 2 prelabral chaetae and the absence of the microsensillum on Abd. I (cf. Figs 79 and 80). The former character was never found in Folsomia species before. Specimens of $F$. bisetosa, including those from the type locality (Jan Mayen) always have 4 prelabral chaetae and the microsensillum on Abd. I present (A. Fjellberg, pers. comm.).

Distribution. Known only from the type locality.

Folsomia sp. aff. stella Grow \& Christiansen, 1976 Material. NESIB: Loc. 57, 3 ex., coll. MSPU.

Affinities. This species, with $3+3$ anterior chaetae on the manubrium and the presence of ventral chaetae on Th. III, resembles species of the $F$. macrochaetosa complex, differing from both $F$. macrochaetosa and F. brevisensilla by the absence of medial macrochaetae on Th. II-III. As a whole it fits the description of $F$. stella, but has only 2 sensilla on Ant. I (vs. 3 sensilla in the original description). This form has been already recorded from northern regions (Norway, Spitsbergen, Alaska) (Christiansen \& Bellinger, 1980; Fjellberg, 1988). Nevertheless, its status remains unclear to us as it is hardly possible from the ecological point of view to find this southern cave species (the types originate from Iowa) in the Arctic.

Distribution. Only one record from the East Palaearctic.

\section{The $F$, macrochaetosa complex}

The species of this group differ from the $F$. fimetaria complex by having $2+2$ macrochaetae on both Th. II and Th. III, and a quadrioculata-like PAO. In addition, the ventral chaetae on Th. III is present, which is uncommon for the $F$. fimetaria complex. The group includes two northern species: $F$. macrochaetosa and $F$. brevisensilla sp. n. F. inoculata Stach, 1947 also belongs to this group. It is widespread in Russia (the Caucasus, Siberia, and Far East), but not in the Arctic regions (middle stretch of Yenisei River is its northernmost record).

Folsomia macrochactosa Martynova, 1977

Material. EAST: Loc. 64, 3 ex. (paratypes), coll. ZMAS.

Distribution. East Palaearctic. Rather common in Subarctic forests (Kamchatka, unpubl.) but has not been found in the tundra zone yet.

\section{Folsomia brevisensilla sp. $\mathrm{n}$.}

Description. In subadult females body length up to 1.5 mm. No ommatidia or traces of pigment. PAO long, slightly wrinkled, with distinct constriction, "denticles" present (Fig. 90). Maxillary palp bifurcated, outer maxillary lobe with 4 sublobal hairs.

4 prelabral chaetae. Ventral side of head with $4+4$ chaetae along linea ventralis. Labium with $4+4$ chaetae. Ant. I, II, III with 2, 3, 1 basal microsensilla and 2, 1, 4-5 (see variability) sensilla, respectively.

Body sensilla short, well differentiated. Sensillar formula for Th. II-Abd. V: 4,3/2,2,2,3,5 (s), 1,0/0,0,0,0,0 


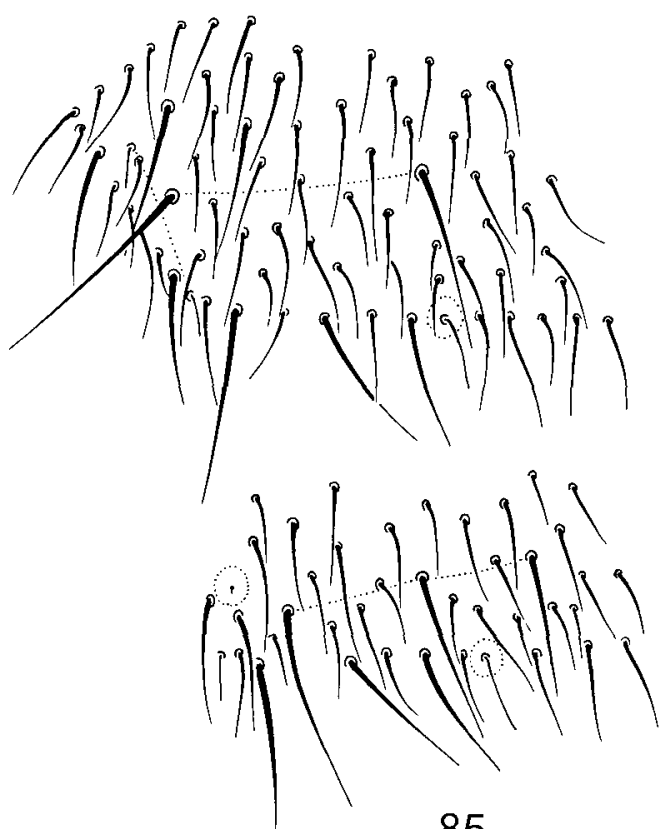

85
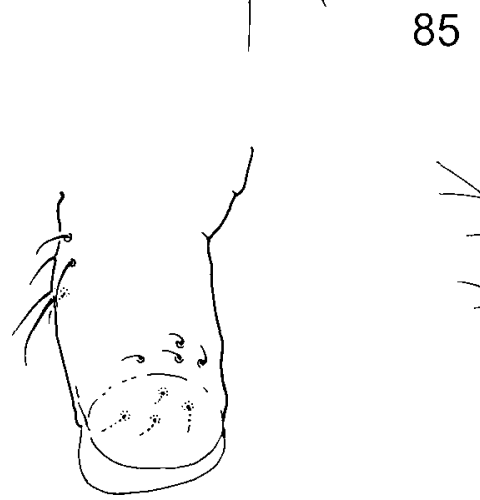

88

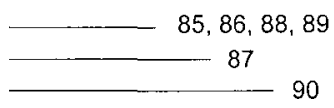

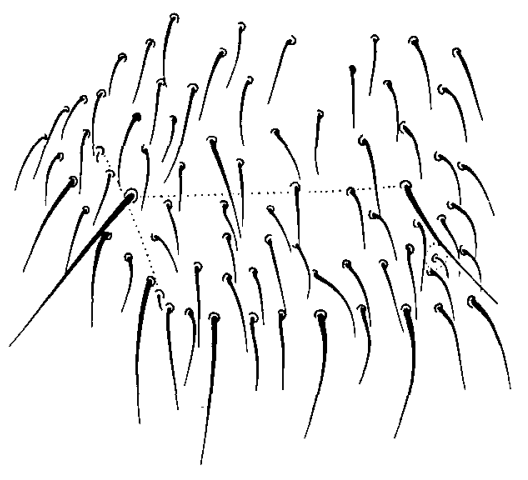

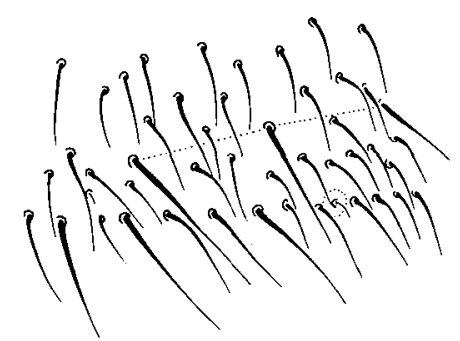

86
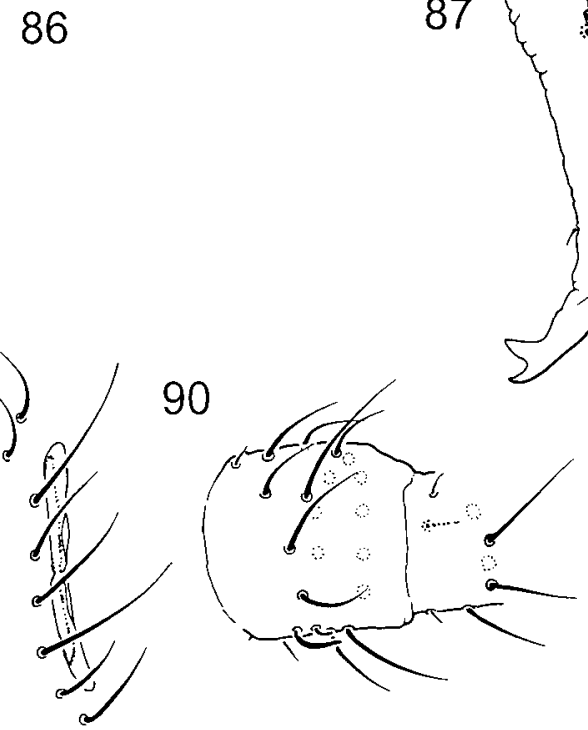

89

Figs 85-90. $85-F$. macrochaetosa, lateral parts of Th. III and Abd. I (paratype). 86-90: F. brevisensilla sp. n. 86 - lateral parts of Th. III and Abd. I; 87 - furca laterally (laterobasal chaetae on posterior side of manubrium not shown); 88 - ventral tube; 89 dorsal chaetotaxy of the end of abdomen; $90-$ PAO, Ant. I and II (basal part). Paratypes. Scale: 0.05 mm.

(ms). Medial sensilla on Th. II-III slightly in front of $\mathrm{p}-$ row of chaetae, those on Abd. I-IV within it (Figs 86, 89). Macrochaetae long and smooth, the longest ones on the last abdominal segments 4 times longer than mucro, their number on Th. II-Abd. IV: 2,2/3,3,3,4. Th. III with 27-30 p-chaetae. Thorax with $2-3+2-3$ ventral chaetae.

Claw without teeth. Tibiotarsi with many additional chaetae. Upper and lower subcoxa with 4-6 and 8 (leg II), 6-8 and 8-10 (leg III) chaetae respectively. Retinaculum with $4+4$ teeth and a chaeta on corpus. Ventral tube with 4+4 latero-distal chaetae and 6-7 posterior ones (Fig. 88). Anterior furcal subcoxa with 14-18 chaetae, the posterior one with 4-5 chaetae. Manubrium with $4+4$ anterior chaetae in two lines (Fig. 87), posteriorly with 6-7+6-7 central, $2+2$ distal, and 1 or 2 apical chactae. Usually with one chaeta on lateral sides of manubrium. Dens crenulated, with 14-17 anterior and 4 posterior chaetae (3 normal basal chaetae and a tiny one in apical part). The middle part of posterior side of dens without of chaetae. Mucro with 2 teeth. Manubrium : dens : mucro as $4.4-5.0: 4.2-5.0: 1$.

Type material. Holotype: 9 (slide), labelled "Russia, Siberia, Kolyma River (delta), left bank, Pohodskaya Edoma, 69³2’ $160^{\circ} 44^{\prime} \mathrm{E}$, tussock tundra on hill top, trough with mosses, 18.-19.vii.1997, leg. A. Babenko", coll. MSPU. Paratypes: 1 specimen from the same region and date but "in damp Eriophorum vaginatum community" and 4 specimens from "hillock of Eriophorum vaginatum with lichen/moss cover".

Additional material. NESIB: Loc. 63, 2 ex., coll. MSPU.

Name derivation. Name reflects the shape of body sensilla (brevis - short in Latin).

Affinities. The new species differs from $F$. macrochaetos $a$ by the short sensilla, the absence of the microsensillum on $\mathrm{Abd}$. I (cf. Figs 85 and 86), and fewer (14-17) 

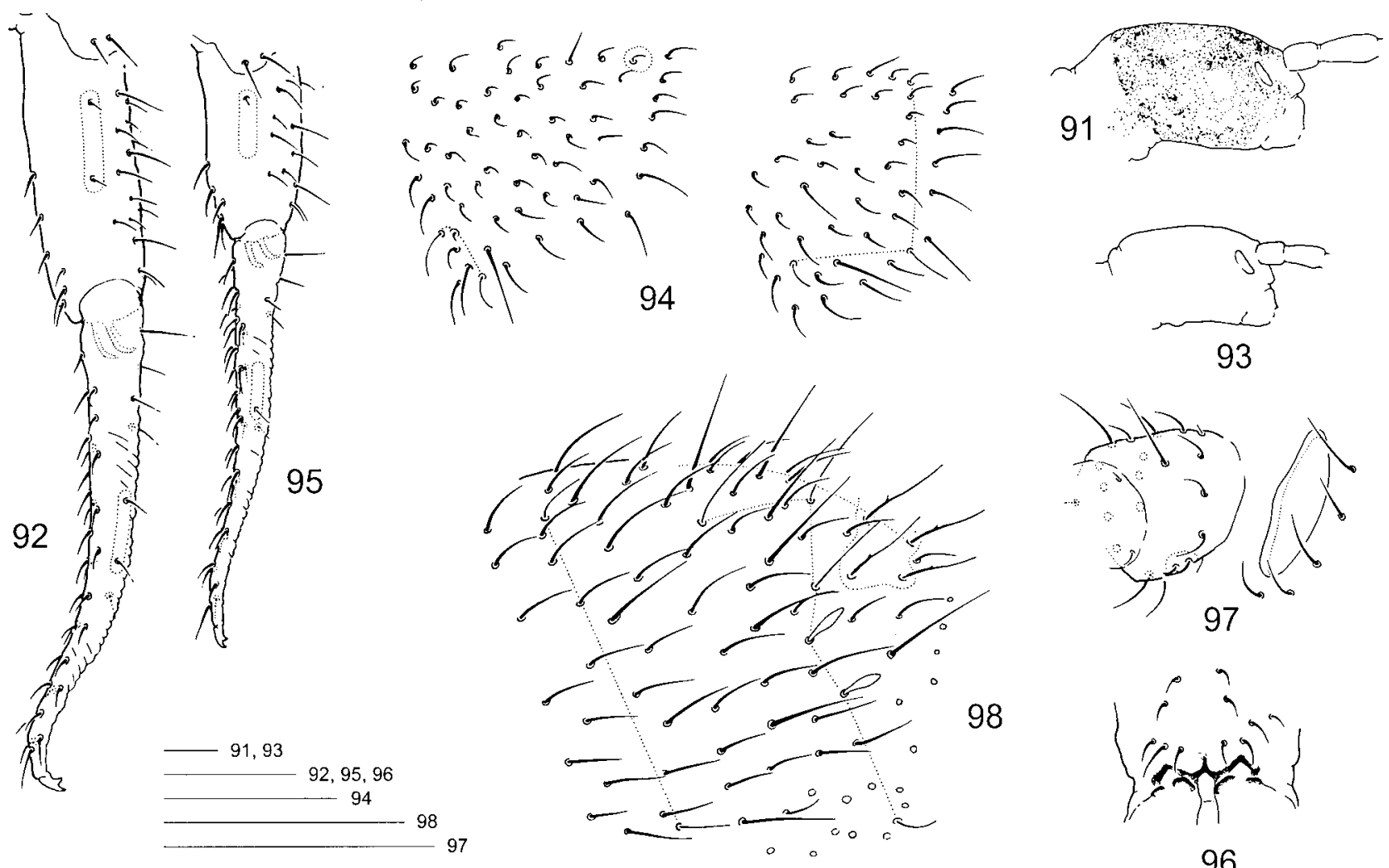

93
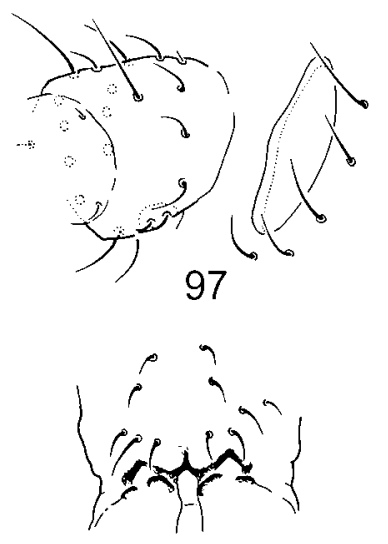

96

Figs 91-98. 91, 92: F. alpha. 91 - color pattern of head; 92 - furca laterally (basal part of manubrium not shown). 93-98: $F$. longidens sp. n. 93 - color pattern of head; 94 - lateral parts of Th. II and III; 95 - furca laterally; 96 - anterior side of manubrium; 97 - PAO and Ant. I-II (basal part); 98 - dorsal chaetotaxy of the abdominal end (sensilla connected, modified chaetae encircled). Scale: $0.05 \mathrm{~mm}$.

anterior chaetae on dens. The most characteristic feature of the new species is the absence of chaetae in the middle part of posterior side of dens. Such condition was known only in some Folsomia species with shortened furca, e.g. F. brevicauda Agrell, 1931 or F. dovrensis Fjellberg, 1976. This feature makes it possible to separate the new species from $F$. stella, which, according to Fig. 6, $F$ of "paratype 1" in Christiansen \& Tucker (1977) bears two chaetae at the middle part of posterior side of dens.

Distribution. Only two records: Lower (southern tundra) and upper (mountainous forest) Kolyma River.

\section{The $F$. sensibilis complex}

Several species having $2+2$ strongly broadened sensilla at the end of abdomen have been described from different parts of the Holarctic, viz.: F. sensibilis Kseneman, 1934 (Carpathians), $F$. tesari Dunger, 1970 (the Sudeten), $F$. gracilis (Stach, 1962) (Spitsbergen), F. alpha Christiansen \& Tucker, 1977 (Alaska), and F. magadani Martynova in Martynova, Berman \& Chelnokov, 1977 (Russia: Magadan Region). Isotoma coeruleogrisea Hammer, 1938 (Canada: NWT) probably also belongs here. All of them have a long furca, many chaetae on anterior side of manubrium (excluding $F$. sensibilis), and no ommatidia: We have found that each side of Abd. V bears 6 sensilla, three slender medial, two leaf- or stick-like in more lateral positions, and one chaeta-like ventrolateral (Fig. 98). The dorsal side of Abd. VI also has some sensillum-like chae- tae. These species form a natural group which should probably be removed from the genus Folsomia in future. Our matcrial from the northern regions includes 4 forms of the complex, two of them are described below as new to science.

The main differences of the species of this complex are summarized in Table 1. Only three of them ( $F$. ancestor; $F$. sensibilis, $F$. longidens) are well distinguished from the relatives. The other members of this group having two outer chaetae in the middle part of dens and an incomplete sensorial set, combine poorly separable taxa which require further study.

\section{Folsomia sensibilis Kseneman, 1934}

Material. EUR: Loc. 25, 3 ex., coll. MSPU; SOUTH: Loc. 76, 1 ex., coll. MSPU; Loc. 78, 1 ex., coll. MSPU.

Affinities. $F$. sensibilis differs from all the other species of the group by having few chaetae on anterior side of dens $(2+2$, rarely $3+3)$. Chaetotaxy of lateral parts of the furca (only one lateral chaeta on each side of manubrium and dens) is also specific and shared only with $F$. longidens sp. n. (see Affinities of the latter).

Distribution. Northern records of this species are restricted to the western Palaearctic: Kola Peninsula, Finland (Vilkamaa, 1989), Norway (Fjellberg, 1988). Not yet found in the true tundra. 
Folsomia alpha Grow \& Christiansen, 1976

Redescription. Diffusely greenish grey, small pigment grains always present, regularly scattered all over the body (Fig. 91). Ant. I, II, III with 2, 1, 6 sensilla and 2, 3, 1 microsensilla. Sensillar formula for Th. II-Abd. V: 3,3/2,2,2,2,6 (s), 1,0/1,0,0,0,0 (ms). On Abd. V three medial sensilla are long, two lateral ones are leaf-like. Macrochaetae short. Ventral chaetae on Th. III present or absent, the following variants were found among adult specimens: $0+0,1+0,1+1,2+0,2+1,2+2,2+3$. Ventral tube with $4+4$ latero-distal chaetae and $4-5$ posterior ones. Manubrium anteriorly with 9-13 chaetae (from 3+2, $1+1,1+1$ to $3+4,1+1,1+1,1+1)$. Manubrium bears two chaetae on each of the lateral sides. Posterior side of dens with 7 chaetae: 4 basal and 3 in middle part (one inner and two outer) (Fig. 92). The position of medial sensilla on the body terga is unstable, often asymmetric: On Th. II-III more usually in front of the p-row, on Abd. I-III as a rule within the p-row.

Material. CSIB: Loc. 54, 1 ex., coll. AB; NESIB: Loc. 56, 5 ex., coll. AB.; Loc. 57, 3 ex., coll. MSPU; AR: NOVISL Loc. 13, 15, 17, 34 ex., coll. MSPU; Loc. 19, 4 ex., coll. AB; EAST: Loc. 66, 1 ex., coll. MSPU; OTHNOR: Loc. 71, 1 ex., coll. MSPU.

Affinities. Two main features distinguish this species from the relatives: Body pigmentation and the posterior position of sensilla on the terga. Unfortunately the latter feature is unstable both in our material and in the type population (Grow \& Christiansen, 1976). F. tesari is also pigmented but differs by having only one chaeta on each of the lateral sides of the manubrium and considerably larger pigment grains on the body. See also Affinities of $F$. janstachi and F. magadani.

Distribution. Distributed only east of Taimyr in the Palaearctic (from Olenek Bay to Chukotka) (Fig. 105). Possibly, this species was recorded as Isotomina coemleogrisea from Wrangel Island (Martynova et al., 1973).

Folsomia janstachi nom. n.

Isotomina gracilis Stach, 1962.

Folsomia gracilis (Stach, 1962) nec Latzel, 1922: Fjellberg, 1984.

Folsomia alpha Grow \& Christiansen, 1976 sensu Fjellberg (1986, 1994).
Redescription. White, no traces of pigment on the body. Ant. I, II, III with 2, 1, 6 sensilla and 2, 3, 1 microsensilla. Sensillar formula for Th. II-Abd. V: $3,3 / 2,2,2,2,6$ (s), 1,0/1,0,0,0,0 (ms). On Abd. V three medial sensilla are long, two lateral ones leaf-like. Macrochaetae rather short, on the last abdominal segments $3.7-4.5$ times longer than mucro, and $0.22-0.25$ times as long as dens. Ventral chaetae on Th. III present, $2+2-3+3$ (rarely $1+1$ ) in number. Manubrium anteriorly with 11-12 chaetae (up to 15). Each lateral side of manubrium bears two chaetae. Dens with 30-36 anterior chaetae. Posterior side of dens with 7 chaetae: 4 basal and 3 in middle part (one inner and two outer). Medial sensilla on Th. II-Abd. III always in front of the p-row.

Material. AR: SPITS Loc. 1, 56 ex., coll. MSPU; Loc. 2, 29 ex., coll. MSPU; SEVZEM Loc. 12, 3 ex., coll. AB; CSIB: Loc. 54, 3 ex., coll. AB; NESIB: Loc. 61, 4 ex., coll. AB; Loc. 62, 1 ex, coll. MSPU.

Affinities. Large collection of this species from Hornsund, southern Spitsbergen (the type locality of Isotomina gracilis) allowed us to ascertain the precise taxonomic position of this species. Fjellberg (1984) sharply defined this form under the name Folsomia gracilis (Stach, 1962) and considered $F$. alpha as its junior synonym. Later Fjellberg (1986) began to use the name alpha instead of gracilis which was preoccupied. We prefer to keep both forms as separate species and thus we propose the new replacement name janstachi, in memory of Jan Stach who originally described it. F. janstachi and $F$. alpha can be distinguished by different body pigmentation (absent vs. present) and the position of sensilla on Abd. I-III (anterior to p-row vs. inside p-row), although the latter character is not stable in F. alpha.

We studied a paratype of Folsomia magadani from "Magadan Region, Snezhnaya Valley" (coll. ZMAS). The specimen differs from $F$. janstachi in having no ventral chaetae on Th. III and more slender sensilla on Abd. V. Obviously the position of $F$. magadani calls for further study but so far it is known only from the type locality and is absent in our materials.

Distribution. Common in Spitsbergen, sporadically all over the Russian Arctic (Fig. 105).

TABLE 1. Diagnostic features of the species of $F$. sensibilis complex.

\begin{tabular}{|c|c|c|c|c|c|c|c|}
\hline Species & $\begin{array}{l}\text { Pigment } \\
\text { on body }\end{array}$ & $\begin{array}{l}\text { No. of ventral } \\
\text { chaetae on Th. } \\
\text { III }\end{array}$ & $\begin{array}{l}\text { No. of anterior } \\
\text { chaetae on } \\
\text { manubrium }\end{array}$ & $\begin{array}{c}\text { No. of chaetae on } \\
\text { lateral sides of } \\
\text { manubrium }\end{array}$ & $\begin{array}{c}\text { No. of outer } \\
\text { chaetae in central } \\
\text { part of dens }\end{array}$ & $\begin{array}{l}\text { No. of } \\
\text { common } \\
\text { sensilla }\end{array}$ & $\begin{array}{c}\text { Position of medial } \\
\text { sensilla on Th. } \\
\text { II-III }\end{array}$ \\
\hline E. ancestor & absent & $0+0$ & $12-13$ & $2+2$ & 2 & $43 / 2223$ & in front of p-row \\
\hline E. sensibilis & absent & $1+1$ & $4-6$ & $1+1$ & 1 & $33 / 2222$ & in front of p-row \\
\hline E. longidens & absent & $0+0$ & $10-12$ & $1+1$ & 1 & $33 / 2222$ & in front of p-row \\
\hline E. janstachi & absent & $2+2-3+3$ & $11-12(15)$ & $2+2$ & 2 & $33 / 2222$ & in front of $\mathrm{p}$-row \\
\hline E. magadani* & absent & $0+0$ & 12 & $2+2$ & 2 & $33 / 2222$ & in front of p-row \\
\hline E. alpha & $\begin{array}{l}\text { diffusely } \\
\text { grey }\end{array}$ & $0+0-2+3$ & $9-13$ & $2+2$ & 2 & $33 / 2222$ & $\begin{array}{l}\text { commonly at the } \\
\text { level witl p-row }\end{array}$ \\
\hline E. tesari* & spotty grey & $0+0-2+2$ & 12 & $1+1$ & 2 & $33 / 2222$ & in front of p-row \\
\hline
\end{tabular}

* The morphological peculiarities of $F$. tesari and $F$. magadani were confirmed by our examination of ten syntypes of the former species from the Sudeten Mts (Heuluder, Braunberg, Maly Staw) and a paratype of the latter from Magadan Region (settlement of Magadan, Snezhnaya Valley). 


\section{Folsomia longidens sp. n.}

Description. Body length up to $0.8 \mathrm{~mm}$. White, no traces of pigment (Fig. 93). Ommatidia absent. PAO about as long as width of Ant. I, 1.8-2.2 times as long as claw. Clear constriction and "denticles" absent (Fig. 97). Maxillary palp bifurcated, outer maxillary lobe with 4 sublobal hairs.

Labral formula $4 / 5,5,4$. Ventral side of head with $4+4$ chaetae along linea ventralis. Labium with $4+4$ chaetae. Ant. I-II with 2 and 1 sensilla. Ant. III with 6 sensilla, arranged as 2 inner, 2 outer and 2 latero-apical. Ant. I with two microsensilla: dorsal and ventral. The second dorsal microsensillum is replaced by a slightly modified "chaeta" of normal size (possibly an enlarged microsensillum). Ant. II and III with 3 and 1 microsensilla, respectively.

Dorsal sensilla rather long; in lateral parts of thorax as long as common chaetae, in medial part slightly shorter. Sensillar formula for Th. II-Abd. V: 3,3/2,2,2,2,6 (s), $1,0 / 1,0,0,0,0$ (ms). Unlike most Folsomia, the following two sensilla are absent: accp-s at the hind corner of Th. II (Fig. 94), and the second medial one on Abd. IV (Fig. 98). Medial accp-sensilla on Th. II-Abd. III situated in front of the p-row but not far from it, on Abd. I-III they are between Mac1 and Mac2. Medial sensilla on Abd. IV nearly within the p-row. On Abd. V the three medial sensilla are almost as long as the macrochaetae, the two lateral sensilla are leaf-like, ventrolateral sensillum hardly differentiated, chaeta-like (Fig. 98). Abd. VI with a group of 7 sensilla-like chaetae, as $3+3$ paired and one unpaired. Macrochaetae short, their number on Th. II-Abd. IV as $2,2 / 3,3,3,4$. Medial ones hardly differentiated, but recognised as erect chaetae. The longest macrochaetae of the last abdominal segments 2.6-3.6 times longer than mucro, and 0.2 as long as dens. Th. III with about 20 chaetae in the p-row. Thorax without ventral chaetae.

Claw toothless. All tibiotarsi with additional chaetae. Upper and lower subcoxa usually with 4 and 7 (leg II), 5 and 6 (leg III) chaetae respectively. Retinaculum with $4+4$ teeth and one chaeta on corpus. Ventral tube with $4+4$ latero-distal chaetae and 5 posterior ones. Anterior furcal subcoxa with 17-22 chaetae, posterior one with 6-8 (9) chaetae. Manubrium with 10-12 anterior chactae (Fig. 96), usually arranged as $3+3,1+1,1+1$ (sometimes $3+3,1+1,1+1,1+0 ; 3+3,1+1,1+1,1+1 ; 3+4, \ldots)$. Posterior side of manubrium with $4+4$ latero-basal, $6-7+6-7$ central, $3+3$ distal, and $1+1$ apical chaetae. There is also an additional chaeta on each lateral side of manubrium. Dens with 29-34 anterior chaetae. Posterior side of dens densely crenulated, with 6 chaetae: 4 basal and 2 in the middle part (inner and outer) (Fig. 95). Mucro short, with 2 teeth. Manubrium : dens : mucro as 7-9:14-18: 1 .

Type material. Holotype: $q$ (slide), labelled "European part of Russia, Kolguev Island, Gol'tsovaya River $\left(69^{\circ} 12^{\prime} \mathrm{N}\right.$, $49^{\circ} 30^{\circ} \mathrm{E}$ ), wet bottom of deep ravine, Salix litter, 27.-28.viii.1994", leg. A. Babenko, coll. MSPU. Paratypes: 7 specimens from the same locality; 1 specimen from the same region, but "shrub tundra", leg. A. Babenko; 8 specimens from "Russia, Novaya Zemlya Archipelago, northern part of South Is- land, Pan'kova Zemlya $\left(73^{\circ} 04^{\prime} \mathrm{N}, 53^{\circ} 10^{\prime} \mathrm{E}\right)$ ", 1995 , three sites of spotted tundra, leg. S. Goryachkin, coll. MSPU.

Additional material. EUR: Loc. 34, 1 ex., coll. AB; URAL: Loc. 37, 1 ex., coll. MSPU; Loc. 38, 1 ex., coll. MSPU; WSIB: Loc. 39, 13 ex., coll. AB; CSIB: Loc. 48, 9 ex., coll. AB; NESIB: Loc. 61, I ex., coll. AB; AR: WRANG Loc. 20, 4 ex., coll. AB; EAST: Loc. 67, 1 ex., coll. MSPU.

Name derivation. Named because of relatively long dens of the new species.

Affinities. The most characteristic feature of $F$. longidens distinguishing it from the other members of the complex, except $F$. sensibilis, is the presence of only one chaeta on each lateral side of the dens and the manubrium (Fig. 95). F. alpha, F. janstachi, F. tesari and F. magadani all have two lateral chaetae on dens.

Chaetotaxy of the lateral side of the manubrium and dens of the new species mostly resembles that of $F$. sensibilis which differs from $F$. longidens by having ventral chaetae on Th. III present, and a lower number of anterior chaetae on the manubrium (4-6 vs. 10-12 in F. longidens).

Distribution. Unclear: It was recorded in two separate regions - western (from Kolguev Island to Taimyr Peninsula) and eastern (Chukotka) but seems to be absent in Novosibirsk Islands (Fig.105), where $F$. alpha is common.

\section{Folsomia ancestor sp. n.}

Description. Body length up to $0.7 \mathrm{~mm}$. Pigment and ommatidia absent. PAO slightly longer than the width of Ant. I (Fig. 101), 2.3-2.8 as long as claw, with weak constriction, "denticles" absent. Maxillary palp bifurcated, outer maxillary lobe with 4 sublobal hairs.

Labral formula $4 / 5,5,4$. Ventral side of head with $4+4$ chaetae along linea ventralis, labium with $4+4$ chaetae. Ant. I with 3 sensilla and 2 microsensilla: dorsal and ventral. The second dorsal microsensillum replaced by a slightly modified "chaeta" of normal size (as in F. longidens). Ant. II and III with 1 and 5 sensilla (2 inner, 2 outer and 1 latero-apical) and 3 and 1 microsensilla, respectively.

Body sensilla rather long. Sensillar formula for Th. II-Abd. V as 4,3/2,2,2,3,6 (s), 1,0/1,0,0,0,0 (ms). Medial accp-sensilla on Th. II-Abd. III situated in front of the prow, on Abd. IV within it. Sensilla on Abd. $\mathrm{V}$ as in $F$. longidens but the two lateral sensilla are stick-like (Fig. 103). Macrochaetae short. Their number on Th. II - Abd. IV as $1,1 / 3,3,3,4$. The longest macrochaetae of the abdominal tip 3.0-3.6 times longer than mucro, and 0.2 as long as dens. Th. III with $20-22$ chaetae in p-row. Thorax without ventral chaetae.

Claw toothless. All tibiotarsi with additional chaetae (Fig. 104). Upper and lower subcoxa usually with 3-4 and 7 (leg II), 6 and 6-7 (leg III) chaetae respectively. Retinaculum with $4+4$ teeth and one chaeta on corpus. Ventral tube with $4+4(4+5)$ latero-distal chaetae and usually 5 posterior ones (Fig. 102). Anterior furcal subcoxa with 18-19 chaetae, posterior one with 7-9 chaetae. Manubrium anteriorly with $3+3(4+3), 1+1,1+1,1+1$ chaetae, posteriorly with $8-10+8-10$ central, $3+3$ distal, 

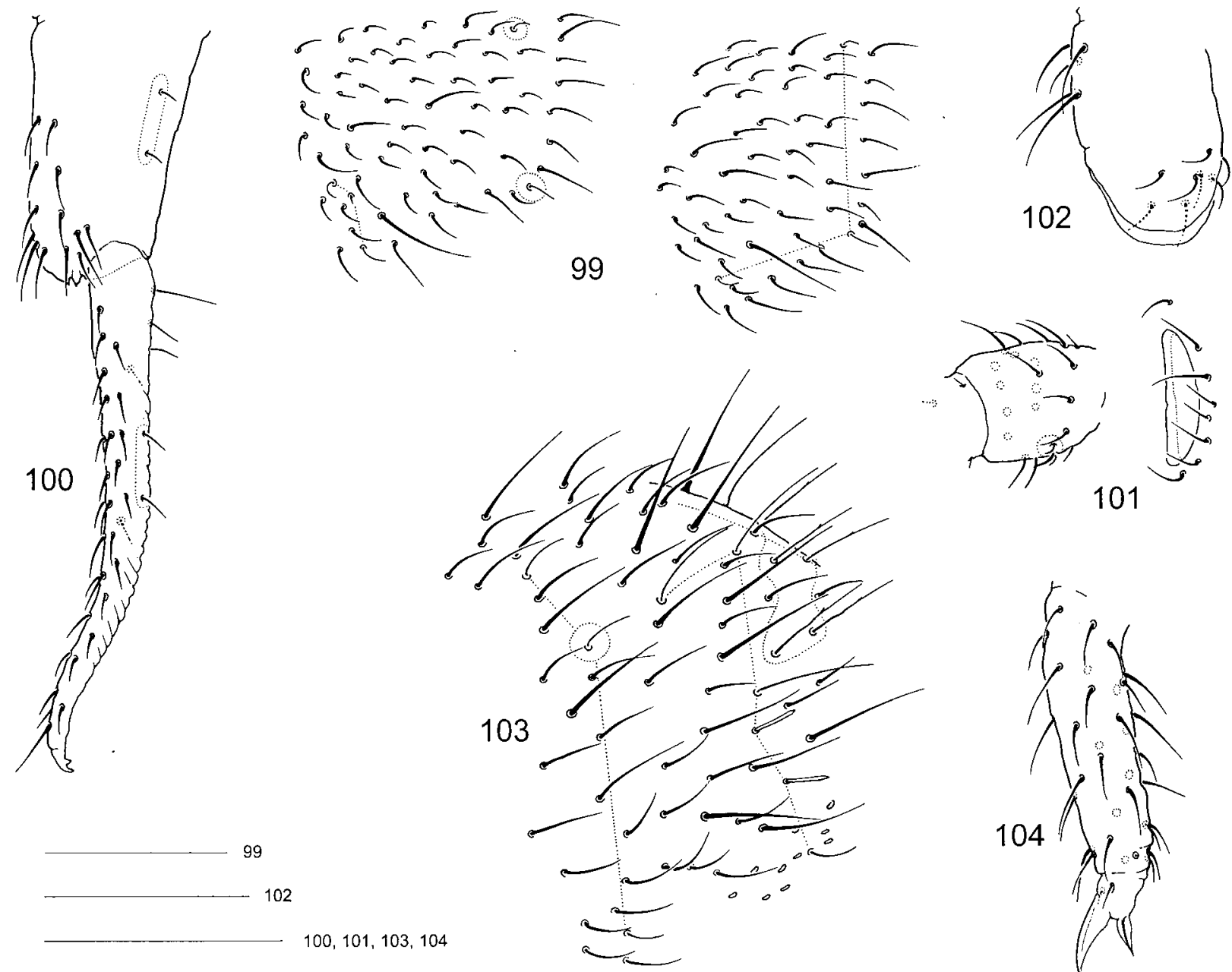

$100,101,103,104$

Figs 99-104: F. ancestor sp. n. 99 - lateral parts of Th. II and III; 100 - furca (basal part of manubrium not shown); 101 - PAO and Ant. I-II (basal part); 102 - ventral tube; 103 - dorsal chaetotaxy of the abdominal end; 104 - tibiotarsus and claw III. Paratypes. Scale: $0.05 \mathrm{~mm}$.

and $1+1$ apical chaetae. Besides, there are two chaetae on each of the lateral sides (Fig. 100). Dens densely crenulated, with 32-34 anterior chaetae, posteriorly with 7 chaetae ( 4 basal and 3 in the middle part). Mucro short, bidentate. Manubrium : dens : mucro as 6-8:13-15: 1 .

Type material. Holotype: ㅇ (slide), labelled "Magadanskaya region, upper Kolyma, ca $60 \mathrm{~km}$ W from Sinegorie vil., Ken- nyubelyakh stream, $1000 \mathrm{~m}$ alt., Dryas community, 10.x.1987", D. Berman leg., coll. MSPU. Paratypes: 4 specimens from the same locality; 2 specimens from the same region, but "Olen stream, birch wood with Calamagrostis, 02.x.1987", D. Berman leg.; 5 specimens from "Sibit-Tyelyakh stream, w slope, $550 \mathrm{~m}$ alt., young birch-wood after fire, 02.x.1987", D. Berman leg.; all coll. MSPU.

TABLE 2 . The lengths of extremities, chaetae and sensilla in the holotypes of the new species.

\begin{tabular}{|c|c|c|c|c|c|c|c|c|c|c|c|c|c|c|c|c|c|c|c|c|}
\hline \multirow{2}{*}{ Species } & \multirow[b]{2}{*}{1} & \multicolumn{4}{|c|}{ Antenna } & \multirow[b]{2}{*}{6} & \multicolumn{4}{|c|}{ Leg III } & \multicolumn{3}{|c|}{ Furca } & \multicolumn{3}{|c|}{ Abd. I } & \multirow{2}{*}{$\frac{\text { Abd. IV }}{17}$} & \multicolumn{3}{|c|}{ Abd. V } \\
\hline & & 2 & 3 & 4 & 5 & & 7 & 8 & 9 & 10 & 11 & 12 & 13 & 14 & 15 & 16 & & 18 & 19 & 20 \\
\hline F. borealis & 1.26 & 35 & 67 & 63 & 125 & 49 & 88 & 88 & 30 & 15 & 120 & 98 & 24 & 49 & 29 & 20 & 15 & 88 & 47 & 29 \\
\hline F. amplissima & 1.53 & 43 & 84 & 88 & 153 & 65 & 118 & 120 & 35 & 20 & 133 & 124 & 29 & 61 & 43 & 29 & 27 & 151 & 69 & 39 \\
\hline F. palaearctica & 0.56 & 17 & 34 & & & 24 & 33 & 35 & 13 & 7 & 43 & 24 & 9 & 13 & 13 & 6 & 8 & 21 & 14 & 7 \\
\hline F. atropolaris & 1.16 & 35 & 57 & & 112 & 47 & 78 & 84 & 27 & 14 & 114 & 88 & 24 & 45 & 33 & 9 & 13 & 86 & 53 & 19 \\
\hline F. cryptophila & 0.45 & 12 & 24 & 26 & 46 & 20 & 31 & & 9 & 6 & & & & 11 & & 10 & 11 & 19 & 17 & 7 \\
\hline F. brevisensilla & 1.34 & 37 & 63 & 59 & 108 & 45 & 94 & 96 & 26 & 16 & 124 & 114 & 29 & 45 & 37 & 4 & 13 & 92 & 25 & 22 \\
\hline F. longidens & 0.69 & 26 & 39 & 43 & 74 & 31 & 58 & 57 & 13 & 9 & 65 & 134 & 9 & 18 & 16 & 12 & 13 & 25 & 22 & 11 \\
\hline F. ancestor & 0.68 & 24 & 43 & 42 & 75 & 30 & 61 & & 15 & 10 & 65 & 129 & 9 & 18 & 17 & 10 & 11 & 30 & 28 & 10 \\
\hline
\end{tabular}

1 - body length; 2-5 - length of Ant. 1-4; 6-PAO; 7 - tibiotarsus; 8 - femur; 9 - claw; 10 - unguiculus; 11 - manubrium; 12 dens; 13 - mucro; 14 - Mac1; 15 - pl-chaeta; 16 - lateral sensillum; 17 - second medial sensillum; 18 - medial macrochaeta; 19 $\mathrm{s}_{2} ; 20-\mathrm{s}_{4}$. Body length is given in $\mathrm{mm}$, others in $\mu \mathrm{m}$. All measurements were made in laterally positioned specimens, body length was measured without antennae. 


\section{F. sensibilis complex}

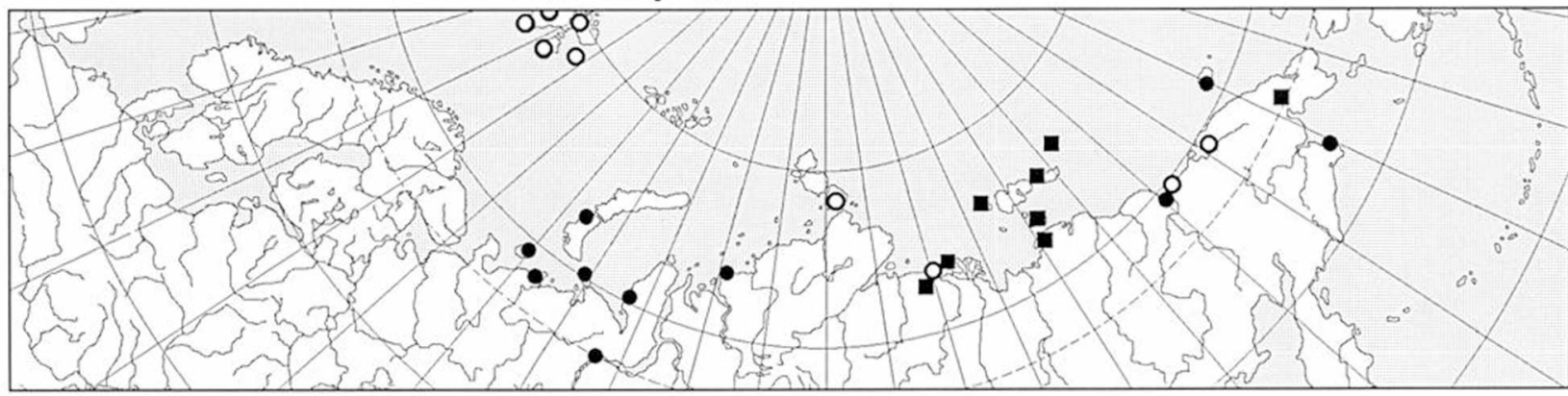

longidens

- janstachi

alpha

\section{F. taimyrica complex}

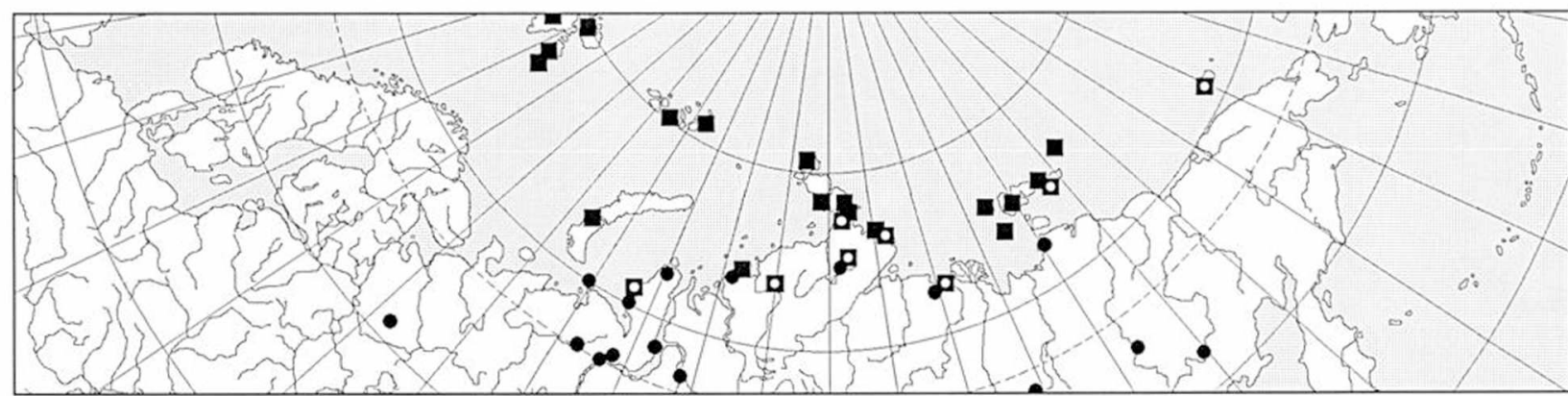

borealis

a taimyrica f. 1

taimyrica f. 2

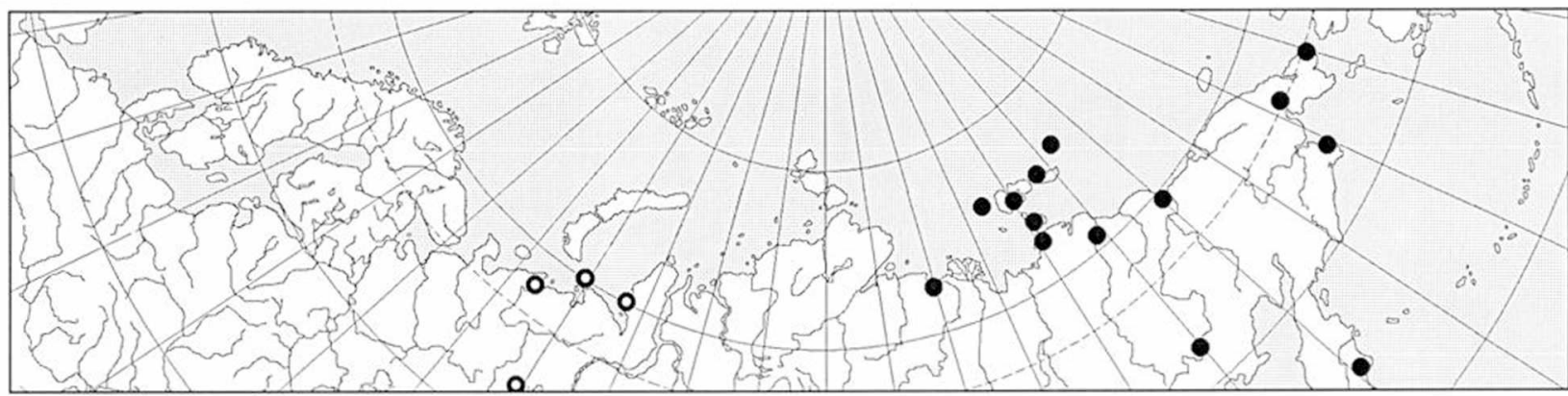

- amplissima o cf. amplissima

Fig. 105. Distribution of species of $F$. sensibilis and F. taimyrica complexes (data for Spitsbergen mainly based on Fjellberg, 1994).

Name derivation. The name reflects the plesiomorphic condition of sensillar chaetotaxy of the new species.

Affinities. The new species is characterized by having the most complete set of sensilla among the members of the F. sensibilis complex (Figs 99, 103). All the others have a reduced number of sensilla on Th. II and Abd. IV. Three sensilla on Ant. I and stick-like (instead of leaf-like) sensilla on Abd. V are also unique characters.

Distribution. Known only from the vicinity of the type locality.

The measurements of the holotypes of the new species are given in Table 2.

\section{IDENTIFICATION KEY TO THE NORTHERN ASIATIC FOLSOMIA}

1 Manubrium with $1+1$ anterior chaetae $\ldots \ldots \ldots \ldots \ldots 2$

- Manubrium with more anterior chaetae ............. 8
2 Ventral tube with $3+3$ lateral chaetae. Posterior side of manubrium with $2+2$ central chaetae $\ldots \ldots \ldots \ldots \ldots 3$ Ventral tube with $4+4$ lateral chaetae. Posterior side of manubrium with $3+3$ or more central chaetae .......6 6

$32+2$ ommatidia. Basal microsensillum on Ant. III present. Pigment on body present, sometimes very dark ..... 4 $1+1$ ommatidia. Basal microsensillum on Ant. III absent. Pigment on body present or absent, usually pale ..... 5

4 "Corner sensillum" on Th. II in front of p-row. Macrochaetae always long. Granulation regularly rugose all over the body. Dens with 8 anterior chaetae ...... quadrioculata

- "Corner sensillum" on Th. II within p-row. Macrochaetae from moderately long to rather short. Granulation finer, coarse granulated belts only at the end of abdomen. Dens with 7 or 8 anterior chaetae ............. manolachei

5 PAO more than 1.5 as long as width of Ant. 1. Upper subcoxa of mid leg with 2-4 chaetae. Macrochaetae moderately long. Dens with 8 anterior chaetae . sp. n. aff. palaearctica 
- PAO equal to or a little longer than width of Ant. I. Upper subcoxa of mid leg with 1 chaeta. Macrochaetae short. Dens with 7 anterior chaetae ............. palaearctica

6 Microsensilla on Abd. II-III absent. Macrochaetae very long. Usually with $2+2$ ommatidia $\ldots \ldots$ amplissima Microsensilla on Abd. II-III present. Macrochaetae moderate or long. No more than $1+1$ ommatidia $\ldots \ldots \ldots .7$

7 Dorsomedial macrochaetae on Th. III present. Ommatidia absent ........................ taimyrica Dorsomedial macrochaetae on Th. III absent. 1+1 ommatidia .......................... borealis

8 Abd. IV-VI with $2+2$ broadened lateral sensilla ..... 9

- Abd. IV-VI without $2+2$ broadened sensilla ...... 13

9 Dens with one lateral chaeta in the middle $\ldots \ldots \ldots 10$

- Dens with two lateral chaetae in the middle ....... 11

10 Manubrium with at most $3+3$ anterior chaetae. Th. III with $1+1$ ventral chaetae $\ldots \ldots \ldots \ldots \ldots . \ldots . \ldots$ sensibilis

- Manubrium with at least $5+5$ chaetae. Th. Ill without ventral chaetae $\ldots \ldots \ldots \ldots \ldots \ldots \ldots$ longidens

11 "Corner sensillum" on Th. II present. Abd. IV with $2+2$ dorsomedial sensilla ................... ancestor

- "Comer sensillum" on Th. Il absent. Abd. IV with 1+1 dorsomedial sensilla $\ldots \ldots \ldots \ldots \ldots \ldots \ldots \ldots \ldots . \ldots \ldots$

12 Gray. Sensilla on abdomen usually within p-row ... alpha

- White. Sensilla on abdomen in front of p-row ... janstachi

13 No ommatidia and pigment. Sensilla on Abd. I-III within p-row $\ldots \ldots \ldots \ldots \ldots \ldots \ldots \ldots \ldots \ldots \ldots . \ldots \ldots$

From $1+1$ to $3+3$ ommatidia. Sensilla on Abd. I-III well in front of p-row ...................... 22

14 Dorsomedial macrochaetae on Th. II-III present. PAO slender. Th. III with ventral chaetae .............. 15

- Dorsomedial macrochaetae on Th. II-III absent. PAO elliptical. Ventral chaetae on Th. III present or absent .... 16

15 Dens without chaetae at the middle of posterior side and with 14-17 anterior chaetae. Medial sensilla on Abd. I-III short

brevisensilla

- Dens with two chaetae at the middle of posterior side and at least 20 anterior chaetae. Medial sensilla on Abd. I-IIl long

......................... macrochaetosa

16 Th. III with ventral chaetae $\ldots \ldots \ldots \ldots$ sp. aff. stella Th. III without ventral chaetae ............. 17

$172+2$ anterior cheatae on manubrium. Macrochaetae short ..

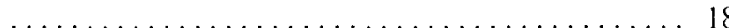

- Usually $3+3$ or more anterior chaetae on manubrium. Macrochaetae long $\ldots \ldots \ldots \ldots \ldots \ldots \ldots \ldots \ldots \ldots \ldots$

18 Microsensillum on Abd. I present. 4 prelabral chactae ....

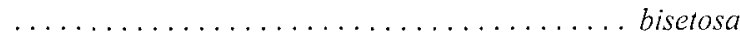

- Microsensillum on Abd. I absent. 2 prelabral chaetae ..... cryptophila

19 Manubrium with 8-15 anterior chaetae. Dens with 4 basal chaetae on posterior side. Sensilla on Th. II-III in front of p-row ....................... sparsosetosa

- Manubrium with at most 10 anterior chaetae. Dens with 3 basal chaetae on posterior side. Sensilla on Th. II-III within

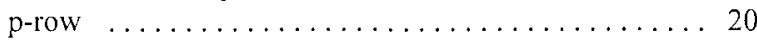

20 Macrochaetae smooth ............... fimetaria

- Macrochaetae clearly ciliated ................ 21

21 Manubrium with $5+5$ anterior chaetae including $3+3$ in distal transversal row ................... nivalis Manubrium with fewer anterior chaetae ....... ciliata

22 Medial sensilla on Abd. II-III between macrochaetae Mac1 and Mac2. Ant. I with 2 sensilla ............. 23

- Medial sensilla on Abd. II-III between macrochaetae Mac2 and Mac3. Chaetae short. Ant. I with 3 sensilla . . . . 27

$233+3$ lateral chaetae on ventral tube $\ldots \ldots \ldots \ldots \ldots 24$
$4+4$ lateral chaetae on ventral tube $\ldots \ldots \ldots \ldots \ldots 26$

24 Basal microsensillum on Ant. III absent. Black or dark grey. Sensilla on body short. Cornea of ommatidia hardly developed .................... atropolaris Basal microsensillum on Ant. III present. Colour paler. Sensilla on body rather long. Cornea of ommatidia well developed ........................ 25

25 Macrochaetae 3.8-4.9 as long as mucro ....... ozeana - Macrochaetae shorter, 2.1-3.4 as long as mucro ........ $\ldots \ldots \ldots \ldots \ldots \ldots \ldots \ldots$. . . aff. ozeana

26 Dorsomedial macrochaetae on Th. III absent .. binoculata Dorsomedial macrochaetae on Th. III present ... regularis

$273+3$ ommatidia. Posterior side of dens with 4 basal chaetae ............................ sexoculata At most $2+2$ ommatidia. Posterior side of dens with 3 basal

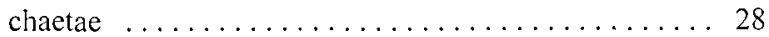

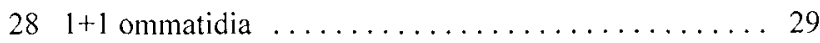
- $2+2$ ommatidia ...................... 30

29 Manubrium with $3+3-5+5$ anterior chaetae diplophthalma - Manubrium with 7+7-9+9 anterior chaetae ..........

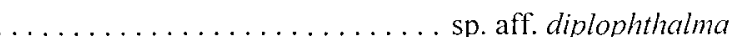

30 White, except ommatidia. "Corner sensillum" on Th. II within p-row ................. microchaeta - Entirely black or dark grey. "Corner sensillum" on Th. II in front of p-row ............... sp. aff. altamontana

ACKNOWLEDGEMENTS. We are much indebted to D. Berman, E. Bondarenko, V. Bulavintsev, C. Chelnokov, M. Chernyakhovsky, Yu. Chernov, K. Eskov, S. Firsova, A. Fjellberg, S. Goryachkin, S. Iordansky, M. Kalinin, O. Kapustyants, V. Karpov, G. Khakhin, S. Kopponen, N. Kuznetsova, G. Lukovtsev, S.F. MacLean, O. Makarova, E. Martynova, I. Netuzhilin, V. Nikolsky, L. Pospelov, I. Stebaev, S. Stebaeva, A. Tichomirova, A. Uvarov, P. Vilkamaa, I. Vtorov for their material, as well as to S.K. Stebaeva, A. Fjellberg and an anonymous reviewer, for important critical remarks and valuable comments.

The paper has been financially supported by the Foundation for the Basic Research of the Russian Academy of Sciences (Projects 96-04-51080, 96-04-51081, 99-04-48165), and by the programme "Biological Diversity", GNTP.

\section{REFERENCES}

Chiristinnsen K. \& Bellinger P. 1980: The Collembola of North America North of the Rio Grande. A Taxonomic Analysis. Grinell College, Grinell, IA, $1322 \mathrm{pp}$.

Cimistiansin K. \& TUCKER D.E. 1977: Four new species of Folsomia (Collembola: Isotomidae). Rev. Ecol. Biol. Sol 14: $371-382$.

Deilarving L. 1982: A propos des Folsomia du groupe quadrioculata Tullberg, 1871. Rev. Ecol. Biol. Sol 19: 613-627.

FJFLLibi:R; A. 1984: Collembola from Jan Mayen, Bjornoya and Hopen with additions to the species list from Spitsbergen. Fauna Norv. (ser. B) 31: 69-76.

FIELLibi:RG A. 1986: Collembola of the Canadian High Arctic. Review and additional records. Can. J. Zool. 64: 2386-2390.

Fuilliberg A. 1988: The Collembola fauna of Troms and Finnmark, North Norway. Fauna Norv. (ser. B) 35: 5-20.

FJilibiriks A. 1994: The Collembola of the Norwegian Arctic islands. Meddr Norsk Polarinst. (Oslo) 133: 1-57.

Grow A.B. \& Cirristinnsin K. 1976: Chaetotaxy of Folsomia (Collembola: Isotomidae) with special reference to Nearctic species. Rev. Ecol. Biol. Sol 13: 611-627.

HAmmLi M. 1954: Collemboles and oribatids from Peary Land (North Greenland). Fauna Arct. 127(4): 4-28. 
Martynova E.F., Gorodkov K.B. \& Tsuelnokov V.G. 1973: [Spingtails (Collembola) of Wrangel Island.] Entomol. Obozr. 52: 76-93 (in Russian).

Potapov M. \& Dunger W. (in press): A redescription of Folsomia diplophthalma (Axelson, 1902) and two new species of the genus Folsomia from continental Asia. Abhandl. Ber. Naturkd. Mus. Görlitz.
Vilkama P. 1989: Records of Collembola new to Finland. Notul. Entomol. 69: 63-65.

Yosil R. 1969: Collembola Arthropleona of the IBP-Station in the Shiga Heights, Central Japan. I. Bull. Natn. Sci. Mus. Tokyo 12: 531-556.

Received January 25, 1999; accepted September 28, 1999 